\title{
Contractual and Organizational Structure with Reciprocal Agents
}

\begin{abstract}
Empirically, compensation systems generate substantial effort despite weak monetary incentives. We consider reciprocal motivations as a source of incentives. We solve for the optimal contract in the basic principal-agent problem and show that reciprocal motivations and explicit performance-based pay are substitutes. A firm endogenously determines the mix of the two sources of incentives to best induce effort from the agent. Analyzing extended versions of the model allows us to examine how organizational structure impacts the effectiveness of reciprocity and to derive specific empirical predictions. We use the UKWERS workplace compensation data set to confirm the predictions of our extended model.
\end{abstract}

JEL Code: D82, J33, M52.

Keywords: optimal contracts, reciprocity, organizational structure.

\author{
Florian Englmaier \\ University of Munich \\ Ludwigstrasse 28 III VG \\ 80539 Munich \\ Germany \\ englmaier@lmu.de
}

\author{
Stephen Leider \\ Harvard University \\ 25 Harvard Way \\ Baker Library $420 \mathrm{~J}$ \\ Boston MA 02163 \\ USA \\ sleider@hbs.edu
}

September 29, 2008

We thank Greg Baron, Tobias Böhm, Nicolas Klein, Georg Gebhardt, Fuhito Kojima, Meg Meyer, Andy Newman, Al Roth, Klaus Schmidt, Carmit Segal, Ferdinand von Siemens, Christian Zehnder and the participants at the European Summer Symposium for Economic Theory 2008 for comments and suggestions. Florian Englmaier thanks the Harvard Business School and the Study Center Gerzensee of the Swiss National Bank for their hospitality and the German Science Foundation (DFG) for financial support via grant EN 784/2-1 and through SFB/TR 15. Stephen Leider thanks the National Science Foundation and the Sperry Fund for financial support. 


\section{Introduction}

Only a fraction of real world labor contracts make substantial use of explicit monetary incentives, and those that do often have only weak monetary incentives. Lemieux et al. (2007) find that in the United States only 37\% of individuals have some kind of pay-forperformance component to their compensation, and that among those who do the median magnitude of these incentives is only $3.5 \%$ of their base wage. ${ }^{1}$ This prevalence of weak (monetary) incentives in real world contracts, while apparently still obtaining non-trivial effort, is not well explained by the standard approach in contract theory which emphasizes the use of output realizations as a (noisy) measure of employee effort to overcome the moral hazard problem. In these models, by tying the level of the agent's compensation to the amount of output produced, the agent is given monetary incentives to increase his output. ${ }^{2}$

We consider reciprocal motivations as a source of incentives and solve for the optimal contract in the basic principal-agent problem with reciprocal agents. We show that reciprocal motivations, i.e. the fact that an individual values positively the utility of someone who has been kind to the individual, and explicit performance-based pay are substitutes and that the use of reciprocal incentives decreases agency costs. In the optimal contract the principal makes use of both forms of incentives, using explicit incentives less when the agent is more reciprocal, and using them more when output is a more informative signal of effort. Reciprocal motivations are more effective when the agent's preference for reciprocity is more pronounced or when it is easier for him to reciprocate, i.e. the benefit to the principal from high effort is larger. This last finding allows us to extend our model to capture features of organizational structure. Interpreting direct supervisors (rather than senior managers) as the workers' relevant principals, we predict a collocation of incentive pay and decision rights for these direct supervisors in the firms that use personality tests (a proxy for firms that care about traits like reciprocity) in their hiring procedure. Furthermore, in those firms incentive pay for non-managers should be less prevalent, i.e. they rely more on reciprocal incentives, and the scope of performance pay for managers should be more narrowly defined. We use the UK WERS workplace survey to confirm our predictions.

\footnotetext{
${ }^{1}$ Belfield and Marsden (2003) and Piekkola (2005) report similar results for the UK (20\% of employees, and $3.5 \%$ of base wages) and Finland (38\% of employees and $3.6 \%$ of base wages). See also Prendergast (1999) for a general survey of empirical tests of the standard contracting model.

${ }^{2}$ Cf. e.g. Holmström (1979), Grossman and Hart (1983), and Holmström and Milgrom (1991). Models that emphasize multitasking in work tasks have been one explanation why weak, rather than strong, incentives prevail. However, such models typically assume directly that the agent is willing to do some positive amount of work absent monetary incentives. The use of career incentives is another potential explanation for the empirical observation.
} 
In the literature alternative sources of incentives in the workplace have been considered before. Akerlof (1982) is an early example. He models the labor relation as a gift exchange where agents respond to generous treatment by the firm (i.e. generous wage packages) by exerting more than minimal effort. While Akerlof's model is based on the effect of work "norms", our paper will build on explicit models of social preferences. In particular we will use "reciprocity", first formally described by Rabin (1993), who employed the psychological games framework of Geanakoplos et al. (1989). ${ }^{3}$

While the basic idea of reciprocity is both simple and appealing - a reciprocal person wants to repay kindness with kindness and mischief with mischief - the application to any but the most simple economic settings is hampered by several problems. 1) In Rabin's model, utility depends on (higher order) beliefs about the other players' actions and the other players' beliefs about own actions etc. 2) An important free parameter in his model is the reference point for a "fair action". In many real world situations it is unclear what the fair reference point is and whether people agree on it. 3) Due to the importance of higher order beliefs there always exist multiple (constructive and destructive) reciprocity equilibria.

Outcome based theories, most notably "inequity aversion" by Fehr and Schmidt $(1999)^{4}$, have been developed to capture important aspects of the gift exchange intuition while avoiding the above mentioned technical complications. ${ }^{5}$ These theories simplify the problem by only conditioning on the final allocations of resources. Hence inequity aversion trades off capturing "reciprocity" directly in preferences for greater tractability. Inequity aversion does capture directly, however, the separate and important phenomenon of "concern for fairness" and does remarkably well in explaining observed behavior in laboratory studies of public good provision, Fehr and Gächter (2000), or contract choices, Fehr, Klein, and Schmidt (2007). However, with weak or no monetary incentives, inequity aversion will only induce effort if either $\mathbf{1}$ ) the agent begins with a larger payoff than the manager, and the manager receives $>50 \%$ of the profit from the agent's effort (thus effort reduces the agent's advantageous inequality) or 2) the agent begins with a smaller payoff than the manager, and the agent receives $>50 \%$ of the profit from his own effort (thus effort reduces the agent's disad-

\footnotetext{
${ }^{3}$ See also the later papers by Dufwenberg and Kirchsteiger (2005) and Falk and Fischbacher (2006) on reciprocity in sequential games and the paper by Cox et al. (2008) grounding reciprocal preferences in neoclassical preference and demand theory.

${ }^{4}$ See also the closely related paper by Bolton and Ockenfels (2000).

${ }^{5}$ See Bartling and Von Siemens (2005), Benjamin (2006), Dur and Glazer (2006), and Englmaier and Wambach (2005) for applications of outcome based models to contracting and incentives, as well as Englmaier (2005) for a survey of this literature, as well as Fehr and Schmidt (2003) for a broader survey of social preferences and decision making.
} 
vantageous inequality). While often true in laboratory gift exchange games, these conditions are generally not met in real world labor market settings; this motivates our development of a reciprocity based model that can generate gift exchange regardless of the principal and agent's relative income and wealth.

Our paper exploits several features of the contracting problem to derive the first full characterization of the structure of optimal contracts with reciprocal agents, providing a theoretical foundation from optimal contracting to "simple" gift exchange reasoning. Moreover, we extend our basic model to capture basic properties of organizational structure and develop a number of predictions that can be tested empirically. We are able to make progress in modeling reciprocity because it is very natural to assume that the particular problems of Rabin's model are absent or at least greatly mitigated in a labor contracting setting. 1) The contract pins down beliefs. This is obviously most true when a contract includes goals or performance thresholds. More generally, in a workplace environment we expect that a firm communicates to a worker the level of performance expected of him (e.g. in a job description or in a code of conduct), which puts his compensation into context. 2) The reservation utility, provided for by the labor market, is a very natural reference point for what constitutes a "fair" action of the firm. Whenever the firm allows the worker to earn a rent above and beyond his next best alternative in the market, this must be interpreted as a kind gesture. The higher the rent, the kinder the firm ought to be perceived. 3) The negative or destructive reciprocity equilibrium does not exist. Due to the agent's individual rationality constraint it is not possible for the firm to make an unkind offer that would be accepted and could result in destructive negative reciprocal behavior by the worker.

We use these natural assumptions to simplify the problem and develop a model capturing the essence of reciprocity. A risk neutral firm hires a risk averse worker to exert nonverifiable effort. As in standard agency models, the worker's risk aversion makes imposing monetary incentives costly. The novelty in our model is that the agent's utility increases in the principal's revenue, i.e. firm profits, whenever the firm provides the agent with a rent in excess of his outside option. Thus when the firm is generous to the agent by giving him something valuable (additional compensation), the agent desires to provide in turn something of value to the firm (higher effort). The agent's intensity of reciprocal concerns is measured by a parameter $\eta$. The agent's reciprocal attitude can now be used by the firm to align the agent's preferences with those of the firm, thus generating intrinsic motivation. Making use of those the firm can substitute away from using explicit incentives, hence offering less performance sensitive contracts. 
The firm can choose whether to make use of the agent's reciprocal attitude or not. The standard incentive contract ${ }^{6}$, which holds the agent down to his outside option, is always feasible. When this contract is implemented, the agent's concern for reciprocity plays no role - the standard contract leaves no rent, hence it is neither kind nor unkind and does not trigger a reciprocal reaction - and the agent reacts to the explicit incentives just as a standard agent would. We can show that there exists a unique $\eta^{*}$ such that for all agents with an $\eta>\eta^{*}$ at least some degree of intrinsic motivation is induced.

We also derive two main comparative statics on the nature of the optimal contract. When the agent is more intrinsically reciprocal, i.e. has a higher $\eta$, or when the effect of the agent's effort on the principal's revenue is greater, then more reciprocal incentives will be used, i.e. the lower will be the extent of explicit incentives as measured by the sensitivity of the agent's remuneration. ${ }^{7}$ In contrast to that, the more informative the signal is with respect to the agent's effort choice, the more explicit incentives will be used. Hence we can show that explicit monetary and implicit reciprocal incentives are substitutes in the principal's optimal incentive mix.

The results of our basic contracting model are difficult to test using real world data as they depend on hard to observe parameters of the model like effort costs, informativeness of profit, or the agent's preference for reciprocity. Hence we take our approach one step further and develop an extension of our basic contracting model, capturing the basic structure of a firm's hierarchy. The predictions we derive are based on observable features of firm hierarchies and we can thus use field data to check our predictions (albeit in a limited fashion).

In the model extension we consider three simple organizational relationships between two managers within the firm to illustrate the role of managerial compensation and decisionmaking for the reciprocity of subordinates. We always assume that the agent feels more reciprocal towards the person deciding about his contract, i.e. the one making the gift. First, we consider a situation with a firm owner and a middle manager. The manager determines the agent's contract, while the owner takes no action. We then vary the strength of the manager's incentives, i.e. his pay-performance sensitivity. This captures how important the agent's effort is for the manager's pay. We show, that stronger managerial incentives make reciprocal incentives more effective, implying less explicit incentives for the worker. Second,

\footnotetext{
${ }^{6}$ I.e., the contract solving the problem with purely selfish agents as laid out by Holmström (1979) or Grossman and Hart (1983).

${ }^{7}$ Englmaier and Leider (2008) test the predictions of our model w.r.t. the relation of the initial gift and the effect of the agent's effort on the principal's revenue both in a lab experiment and in a field experiment and find supportive evidence in both cases.
} 
we consider a situation where the two managers are supervising different agents who work independently. Each manager determines the contract for his agent. We then vary whether the managers' incentives are narrow (depending only on the revenue generated by their agent) or broad (depending on the total revenue). It turns out that more narrow incentives improve the effectiveness of reciprocal incentives as they better target the worker's return gift to "his" manager. Thirdly, we consider a situation where one manager is the agent's direct supervisor (whose compensation is highly dependent on the agent's output) and the other is a senior manager (whose compensation is weakly dependent on the agent's output). We consider the effect of having the agent's pay set centrally (by the senior manager) versus giving the supervisor discretion over pay, i.e. having him set the contract and show that the manager whose pay is more dependent on the agent's performance should be responsible for setting pay.

Summing up, the results of our model suggest that, if a firm uses reciprocal incentives as a part of its incentive package, several parts of the firm's personnel policy should be coordinated to maximize the effectiveness of reciprocal incentives. We take this prediction and compare it to the data features of the 1998 wave of the WERS UK data set $^{8}$ which includes information on hierarchies, the use of explicit incentives and the use of personality tests. We interpret the use of personality (instead or in addition to ability) tests as a sign of firms screening for reciprocal workers (or at least identifying firms likely to have highly reciprocal workforces). This is in line with the arguments brought forward in Autor and Scarborough (forthcoming) on the hiring practices of a large retail firm and the findings in Ashton et al (1997), Ben-Ner et al (2004), and Englmaier and Leider (2008) where it is demonstrated that personality traits that are usually identified with personality tests like the "Big 5 Test" are closely related to reciprocity as usually defined in laboratory experiments. We predict that in firms that use personality tests (i.e. have a reciprocal workforce) there should be a collocation of middle managers having decision rights over worker pay (i.e. the managers are directly "sending a gift"), incentive pay for those managers (i.e. a high value of the return gift, effort, to the initial sender), and flat wages (specifically less usage of incentive pay) for workers, implying that reciprocity is substituting for monetary incentives. Note that this prediction for flat wages is quite conservative: we can only distinguish in the data firms completely substituting away from monetary incentives, rather than a partial reduction in the magnitude of monetary incentives (which would also be consistent with our

\footnotetext{
${ }^{8}$ For information on the WERS see:

http://www.berr.gov.uk/employment/research-evaluation/wers-98/index.html.

The data set is available at:

http://www.esds.ac.uk/findingdata/snDescription.asp?sn=4026\&key=WERS.
} 
model). Analyzing the cross-section of firms, we find the relevant interaction with the use of personality test to be negative and highly significant and hence confirming our model's predictions.

Our suggestive evidence connecting gift exchange with organizational structure indicates a new direction for research in the growing empirical literature on gift exchange in the field. For example Falk (2007) documents an increase in donations if solicitation letters include a present for potential donors and Leuven et al (2005) provide survey evidence that firms with a more reciprocal work force are more likely to provide their workers with general training (as they deem it more likely that this gift will be repaid within an ongoing relation). However, Gneezy and List (2006) ran a field experiment hiring students for a day job and find that the effect of gift exchange in the field is only minor, fast disappearing and overall not a viable employment strategy. In contrast, Kube et al. (2006), in a setting similar to Gneezy and List's, find weak evidence for the presence of (positive) gift exchange and strong evidence for negative reciprocity as a response to wage cuts. Also Bellemare and Shearer (2006) analyze gift exchange within a real tree planting firm in British Columbia and find persistent effects of gift exchange. Moreover they argue that spot market field experiments only establish a lower bound of the effects of gift exchange in real firms that are characterized by longstanding and ongoing relations that amplify the effects. Finally, Dohmen et al. (2008) provide detailed survey evidence from the German Socio Economic Panel (GSOEP) for the prevalence of reciprocity on a representative level. They find substantial heterogeneity in the degree of reciprocity, measured by the participants' response to six different survey questions. They distinguish between positive, which is the focus of our analysis, and negative reciprocity. They proxy effort with measures of working hours and overtime hours and find that positively reciprocal workers exert more of both. Moreover they find that positively reciprocal people are less likely to be unemployed.

The rest of the paper is structured as follows. The next section sets out and analyzes our contracting model, the following section 3 starts with the description of an extended version of our contracting model and takes it to the WERS data. Section 4 concludes. The Appendix contains proofs and tables. 


\section{The Baseline Model}

\subsection{Model Set Up}

We begin by considering a moral hazard model with one risk neutral principal who wants to maximize expected profits and one risk averse agent who cares about reciprocity. We assume that there are $n$ states of the world that are characterized by outputs $q_{i}$ with $i=1, \ldots, n$ respectively. The agent can take one of two actions ${ }^{9}$ (effort levels) $a_{1}$ and $a_{2}$ with $a_{1}<a_{2}$ and corresponding costs from effort $c(\cdot)$ with $c\left(a_{2}\right)>c\left(a_{1}\right)$. The two actions imply respective probabilities of the states $\pi_{i}\left(a_{1}\right)$ and $\pi_{i}\left(a_{2}\right)$ where for the respective expected return of the principal $\sum \pi_{i}\left(a_{2}\right) q_{i}>\sum \pi_{i}\left(a_{1}\right) q_{i}$ holds. As is standard, we assume that the monotone likelihood ratio property (MLRP) holds, i.e. that $\frac{\pi_{j}\left(a_{2}\right)}{\pi_{j}\left(a_{1}\right)}>\frac{\pi_{i}\left(a_{2}\right)}{\pi_{i}\left(a_{1}\right)}$ for all $j>i$. Hence higher states are better signals of high effort.

A contract $\left(w_{i}, \hat{a}\right)$ is a set of wage payments $w\left(q_{i}\right)$ in each state, as well as a (non-binding) request for an action $\hat{a}$. In a real world context we could think of $\hat{a}$ as an informal job description or a code of conduct. While $\hat{a}$ is not enforceable, it serves to fix the agent's beliefs about the principal's intended generosity (since the expected utility of a contract depends on the agent's action).

The agent's inherent concern for reciprocity is measured by $\eta \in[0,+\infty)$. The agent's utility function given that he takes action $a^{\prime}$, under the contract $(w, \hat{a})$, is given by

$$
U\left(a^{\prime}, \hat{a}\right)=\sum \pi_{i}\left(a^{\prime}\right) u\left(w_{i}\right)+\eta\left(\sum \pi_{i}(\hat{a}) u\left(w_{i}\right)-c(\hat{a})-\bar{u}\right)\left(\sum \pi_{i}\left(a^{\prime}\right) q_{i}\right)-c\left(a^{\prime}\right) .
$$

We assume that $u(\cdot)$ is a real-valued, continuous, strictly increasing, concave function defined on some open interval $(u(\underline{w}), \infty)$ where $\underline{w}$ is finite, and $\lim _{w \rightarrow \underline{w}} u(w)=-\infty$.

The utility function consists of three parts ${ }^{10}$ :

i) expected utility from the monetary wage payment $\sum \pi_{i}\left(a^{\prime}\right) u\left(w\left(q_{i}\right)\right)$.

\footnotetext{
${ }^{9}$ We address the multi-action case in Appendix 5.6

${ }^{10}$ Compare this with Rabin's (1993) initially suggested reciprocal utility function. Rabin (1993, pp. 12867) writes the expected utility function for player i as

$$
U_{i}\left(a_{i}, b_{j}, c_{i}\right)=u_{i}\left(a_{i}, b_{j}\right)+\tilde{f}_{j}\left(b_{j}, c_{i}\right)\left[1+f_{i}\left(a_{i}, b_{j}\right)\right]
$$

where $u_{i}\left(a_{i}, b_{j}\right)$ is the monetary payoff to player $\mathrm{i}, \tilde{f}_{j}\left(b_{j}, c_{i}\right)$ is player i's belief about how kind player $\mathrm{j}$ is being to him, and $f_{i}\left(a_{i}, b_{j}\right)$ is how kind player $\mathrm{i}$ is being to player $\mathrm{j}$ (relative to a benchmark taken to be the average of the highest and lowest possible payoffs). Thus negative reciprocity $\left(\tilde{f}_{j}<0\right.$ and $\left.f_{i}<-1\right)$ as well as positive reciprocity increases utility.
} 
ii) reciprocal utility $\eta\left(\sum \pi_{i}(\hat{a}) u\left(w\left(q_{i}\right)\right)-c(\hat{a})-u_{0}\right)\left(\sum \pi_{i}\left(a^{\prime}\right) q_{i}\right)$.

iii) effort $\operatorname{costs} c\left(a^{\prime}\right)$.

Hence a "generous" contract is one that provides a rent to the agent, i.e. an expected monetary utility in excess of the agent's outside option. A more generous contract (i.e. one that provides a larger rent) will induce the agent to feel more reciprocal, which here means that he will derive greater marginal and absolute utility from the principal's revenue. ${ }^{11}$

We follow the approach of Grossman and Hart (1983) and focus on the implementation problem for a particular action and do not consider the second stage problem of choosing the optimal action, which is generally intractable for more than two actions. In the two action case we focus on implementing $a_{2}$, as $a_{1}$ can be implemented trivially. The principal's problem is to solve the following program:

$$
\begin{gathered}
\min _{w\left(q_{i}\right), \hat{a}} \sum \pi_{i}\left(a_{2}\right) w\left(q_{i}\right) \\
\text { s.t. }[I R] \quad U\left(a_{2}, \hat{a}\right) \geq \bar{u} \quad[I C] \quad U\left(a_{2}, \hat{a}\right) \geq U\left(a_{1}, \hat{a}\right) \quad[E B] \quad \hat{a}=a_{2}
\end{gathered}
$$

The first and second constraints are the standard individual rationality $[\mathrm{IR}]^{12}$ and incentive compatibility $[\mathrm{IC}]$ constraints. The third constraint requires that beliefs are in equilibrium [EB], i.e. that it is proper for the agent to interpret the intended kindness of the principal's contract offer as his expected rent under action $\hat{a}$. Effectively, $[\mathrm{EB}]$ is an equilibrium selection assumption where we are making a substantive restriction (each contract maps to one belief - ruling out babbling equilibria) and a wlog restriction (equating the belief induced to the actual communication). The $[\mathrm{IC}]$ and $[\mathrm{EB}]$ constraints together ensure that the principal is asking for the action he is attempting to implement.

However, note that it is sufficient to simply assume $[\mathrm{EB}]$ and solve to implement $\hat{a}=a_{2}$ :

$$
\min _{w\left(q_{i}\right)} \sum \pi_{i}(\hat{a}) w\left(q_{i}\right) \quad \text { s.t. } \quad U(\hat{a}, \hat{a}) \geq \bar{u} \quad \text { and } \quad U(\hat{a}, \hat{a}) \geq U\left(a_{1}, \hat{a}\right) .
$$

Now we make the standard transformation

$$
w_{i}=h\left(u\left(w_{i}\right)\right), \quad h(\cdot)=u^{-1}(\cdot), \quad h^{\prime}(\cdot)>0, \quad h^{\prime \prime}(\cdot)>0
$$

\footnotetext{
${ }^{11}$ Note that, in order to ease exposition and to focus on our main idea, we use the principal's gross revenue, instead of revenue net of the wage payment. We want as simply as possible capture the intuition that leaving a rent to the agent aligns his interests to the principal's interests.

${ }^{12}$ We assume the outside option to be exogenously fixed. It would be interesting, though beyond the scope of this paper, to consider endogenizing the outside option in a competitive labor market with similar firms solving simultaneously the same problem. To justify our assumption here, think of the presence of match specific capital, i.e. the worker prefers ceteris paribus for reasons not explicitly modeled here, this firm over his next best alternative.
} 
The following notational definitions will sometimes be helpful:

$$
\begin{array}{ll}
u_{i}=u\left(w\left(q_{i}\right)\right) & E R(\hat{a})=\sum \pi_{i}(\hat{a}) q_{i} \\
\Delta c=c(\hat{a})-c\left(a_{1}\right) & \Delta E R=\sum \pi_{i}(\hat{a}) q_{i}-\sum \pi_{i}\left(a_{1}\right) q_{i}
\end{array}
$$

Additionally, we can transform the [IR] into a more useful form:

$$
\begin{array}{r}
U(\hat{a}, \hat{a})=\sum \pi_{i}(\hat{a}) u_{i}+\eta\left(\sum \pi_{i}(\hat{a}) u_{i}-c(\hat{a})-\bar{u}\right) E R(\hat{a})-c(\hat{a}) \geq \bar{u} \\
(1+\eta E R(\hat{a}))\left(\sum \pi_{i}(\hat{a}) u_{i}-c(\hat{a})-\bar{u}\right) \geq 0 \\
\sum \pi_{i}(\hat{a}) u_{i}-c(\hat{a})-\bar{u} \geq 0
\end{array}
$$

and similarly for the $[\mathrm{IC}]$

$$
\begin{aligned}
U(\hat{a}, \hat{a}) & \geq U\left(a_{1}, \hat{a}\right) \\
\sum\left(\pi_{i}(\hat{a})-\pi_{i}\left(a_{1}\right)\right) u_{i}+\eta\left(\sum \pi_{i}(\hat{a}) u_{i}-c(\hat{a})-\bar{u}\right)(\Delta E R) & \geq \Delta c
\end{aligned}
$$

Thus the principal's full problem is given by

$$
\begin{aligned}
& \min _{u_{i}} \sum \pi_{i}(\hat{a}) h\left(u_{i}\right) \quad \text { s.t. } \sum \pi_{i}(\hat{a}) u_{i}-c(\hat{a})-\bar{u} \geq 0 \\
& \text { and } \sum\left(\pi_{i}(\hat{a})-\pi_{i}\left(a_{1}\right)\right) u_{i}+\eta\left(\sum \pi_{i}(\hat{a}) u_{i}-c(\hat{a})-\bar{u}\right)(\Delta E R) \geq \Delta c
\end{aligned}
$$

As in the standard problem, we now have a convex minimization problem with a finite number of linear inequality constraints. Therefore the Karush-Kuhn-Tucker conditions are necessary and sufficient. However, first we wish to build intuition about the principal's problem. Examining the $[\mathrm{IC}]$, we can see that when the agent is reciprocal $\eta>0$, the principal has two means of providing incentives. First, the principal can provide monetary incentives as in the standard problem. Second, the principal can provide the agent with a positive rent, thus engendering reciprocity. The former is costly as it exposes the risk averse agent to a risky income stream for which the agent has to be compensated with a risk premium, while the latter involves an excess payment in order to provide the agent with a rent. The principal's task is to mix these two incentives optimally.

\subsection{Extreme Contracts}

Before solving for the general optimal contract, it is useful to make the following observations about the standard (selfish-agent) contract and a flat-wage contract - two extremes in terms of monetary and reciprocal incentives. 
Observation 1 For $\eta=0$ the standard contract is optimal.

This is straightforward to see since for $\eta=0$ the principal's problem collapses to the standard problem

$$
\begin{aligned}
& \min \sum \pi_{i}(\hat{a}) h\left(u_{i}\right) \\
& \text { s.t. } \sum\left[\pi_{i}(\hat{a}) u_{i}-c(\hat{a})\right] \geq \bar{u} \quad \text { and } \quad \sum\left[\pi_{i}(\hat{a})-\pi_{i}(a)\right] u_{i} \geq \Delta c
\end{aligned}
$$

with the classic solution: $h^{\prime}\left(u_{i}\right)=\lambda_{I R}+\lambda_{I C}\left[1-\frac{\pi_{i}(a)}{\pi_{i}(\hat{a})}\right]$.

Hence our expansion of the problem to consider reciprocal agents nests the standard problem as a special case.

Observation 2 The optimal standard contract implements $\hat{a}$ for any $\eta$.

It is well known that the optimal contract in the standard problem holds the agent down to his outside option, $E U=\bar{u}$. Hence the agent has zero rent, and the reciprocal portion of his utility drops out. Therefore, since the standard contract meets the $[\mathrm{IC}]$ of the standard problem, it also meets the [IC] of the full problem. This means that a reciprocal agent who has been given zero rent acts like a selfish agent. Thus if a firm were to use a standard incentive contract for its workers, even any reciprocal individuals within the workforce would still exert effort. The firm would not observe too-low productivity, it would merely have a (potentially) higher-than-necessary labor cost.

More generally, we can prove the following lemma for any contract:

Lemma 1 If a contract $\left(w_{i}, \hat{a}\right)$ implements $\hat{a}$ for $\eta_{1}$, then it implements $\hat{a}$ for all $\eta_{2} \geq \eta_{1}$.

Proof. It is clear that the [IR] is invariant to $\eta$. Similarly, the RHS of the [IC] does not vary with $\eta$. The LHS $\left(L H S_{I C}=\left[\sum\left(\pi_{i}(\hat{a})-\pi_{i}\left(a_{1}\right)\right) u_{i}+\eta\left(\sum \pi_{i}(\hat{a}) u_{i}-c(\hat{a})-\bar{u}\right)(\Delta E R)\right]\right)$ is increasing in $\eta: \frac{\partial L H S_{I C}}{\partial \eta}=\left(\sum \pi_{i}(\hat{a}) u_{i}-c(\hat{a})-\bar{u}\right)(\Delta E R) \geq 0$.

Therefore, when the agent is more reciprocal the set of feasible contracts increases, and thus the principal's agency costs are non-increasing in $\eta$.

Let $V(\eta, \Delta E R ; \hat{a})=\min _{u} \sum_{i} \pi_{i}(\hat{a}) h\left(u_{i}^{*}\right)$ denote the value function to the principal's problem (i.e. the expected wage bill), where $u^{*}$ is the optimal contract. Then the lemma immediately implies

Proposition $1 V(\eta, \Delta E R ; \hat{a})$ is non-increasing in $\eta$ for all $\hat{a}$. 
Hence it will be cheaper for the principal to induce a more reciprocal agent to exert effort than a less reciprocal agent. Moreover, since in the $[\mathrm{IC}] \eta$ is multiplied by $\Delta E R$ we can directly conclude that increasing the value of output to the principal (i.e. increasing $\Delta E R$ ) has the same consequences.

Corollary 1 1. For any $\eta$, if a contract $\left(w_{i}, \hat{a}\right)$ implements $\hat{a}$ for $\Delta E R_{1}$, then it implements $\hat{a}$ for all $\Delta E R_{2} \geq \Delta E R_{1}$. 2. For any $\eta, V(\eta, \Delta E R ; \hat{a})$ is non-increasing in $\Delta E R$ for all $\hat{a}$

Focusing now on the opposite extreme of a flat wage, where there are no explicit monetary incentives, we can also easily see that reciprocal agents can still be induced to work hard. Thus reciprocal motivations are a separate lever to provide incentives and can be sufficient on their own.

Observation 3 For $\eta>0$ a flat wage with a large enough rent $\tilde{u}$ will implement $\hat{a}$.

Consider $u_{i}=\bar{u}+c(\hat{a})+\tilde{u}$ for all $i$, where $\tilde{u}>0$. Since we assume a positive rent, the $[\mathrm{IR}]$ will be met. Consider the $[\mathrm{IC}]$ :

$$
\begin{aligned}
\sum\left(\pi_{i}(\hat{a})-\pi_{i}(a)\right) u_{i}+\eta\left[\sum \pi_{i}(\hat{a}) u_{i}-c(\hat{a})-\bar{u}\right](\Delta E R) & \geq \Delta c \\
(\bar{u}+c(\hat{a})+\tilde{u})\left(\sum\left(\pi_{i}(\hat{a})-\pi_{i}(a)\right)\right)+\eta\left[\sum \pi_{i}(\hat{a})(\bar{u}+c(\hat{a})+\tilde{u})-c(\hat{a})-\bar{u}\right](\Delta E R) & \geq \Delta c \\
\eta(\tilde{u})(\Delta E R) & \geq \Delta c
\end{aligned}
$$

Clearly the $[\mathrm{IC}]$ can be met for $\tilde{u}$ large enough: $\tilde{u} \geq \frac{\Delta c}{\eta \Delta E R}$. Thus, if agents are sufficiently reciprocal, a firm can still induce effort even if contracts are completely invariant w.r.t. signals of good performance. In fact, for very reciprocal agents the principal can induce effort quite cheaply, approaching the first best implementation cost.

Observation 4 For $\eta \rightarrow \infty$ the First Best is arbitrarily closely approximated with a flat wage with an infinitesimal rent.

From equation (2.2) above, it is clear that as $\eta$ increases, the rent needed to induce the agent to exert effort decreases. In particular, in the limit the rent needed is zero. Hence the principal's cost to implement $\hat{a}$ is merely the outside option plus the cost of effort, equal to the First Best cost. 


\subsection{The Optimal Contract}

Returning to the Principal's full problem, we can now form the Lagrangian and solve for the optimal $u_{i}$.

The First Order Condition for $u_{i}$ in the principal's problem is given by

$$
\begin{aligned}
0 & =\pi_{i}(\hat{a}) h^{\prime}\left(u_{i}\right)-\lambda_{I R} \pi_{i}(\hat{a})-\lambda_{I C}\left[\pi_{i}(\hat{a})-\pi_{i}(a)+\eta \pi_{i}(\hat{a})(E R(\hat{a})-E R(a))\right] \\
h^{\prime}\left(u_{i}\right) & =\lambda_{I R}+\lambda_{I C}\left[1-\frac{\pi_{i}(a)}{\pi_{i}(\hat{a})}+\eta(E R(\hat{a})-E R(a))\right] .
\end{aligned}
$$

with complementary slackness $\lambda_{I R} *[I R]=0$ and $\lambda_{I C} *[I C]=0$ with $[I R]$ and $[I C]$ denoting the $[\mathrm{IR}]$ and $[\mathrm{IC}]$ constraints respectively. For further analysis the following lemma will be helpful.

Lemma 2 IC binds at the optimum for all $\eta$.

Proof. First suppose the $[\mathrm{IC}]$ and the $[\mathrm{IR}]$ are both slack. Then an alternative contract $u_{i}^{\prime}=u_{i}-\epsilon$ will still meet the [IR] and [IC] for small enough $\epsilon$, yet cost the principal strictly less. Next, suppose the [IC] is slack, but the [IR] binds. In this case, the contract provides no rent to the agent, hence the reciprocal portion of his utility drops out. Therefore the agent acts like a selfish agent, and the logic from the standard problem carries through: if the $[\mathrm{IC}]$ were slack the FOC's would imply a flat wage, however a flat wage does not provide any monetary incentives to exert effort - violating the $[\mathrm{IC}]$. Therefore the $[\mathrm{IC}]$ must bind for all $\eta$.

Hence there are two classes of optima that we must consider:

1) Contracts where both the $[\mathrm{IC}]$ and the $[\mathrm{IR}]$ bind.

2) Contracts where the $[\mathrm{IC}]$ binds and the $[\mathrm{IR}]$ is slack.

To show that the latter case is relevant, we can also directly prove that for $\eta$ sufficiently large, the optimal contract will provide the agent with a rent.

Proposition 2 There exists a finite $\eta^{*}$ such that for all $\eta \leq \eta^{*}$ the optimal contract is a standard contract (i.e. provides zero rent) and for all $\eta>\eta^{*}$ the optimal contract is a reciprocity contract (i.e. provides the agent with a strictly positive rent).

The full proof is in Appendix 5.1, however we can easily demonstrate that for some parameter range a reciprocity contract is optimal, and thus provide an upper limit for $\eta^{*}$. Since the 
standard contract (and its cost to the principal) is invariant to $\eta$, to show that a reciprocity contract is sometimes optimal it is sufficient to show that some (non-optimal) reciprocity contract implements $\hat{a}$ at lower cost to the principal. Let $u_{s t}$ be the standard contract, and let $\tilde{w}=\sum \pi_{i}(\hat{a}) h\left(u_{s t, i}\right)$ be the principal's expected cost for the standard contract. Consider the flat wage $u_{i}=u(\tilde{w}-\epsilon)=\tilde{u}$ for some small $\epsilon$. Clearly, this contract has strictly lower cost for the principal. If $\epsilon$ is small enough, this flat wage will still satisfy the [IR] and provide the agent with a positive rent (since the agent is risk averse). Moreover, it will satisfy the $[\mathrm{IC}]$ if

$$
\eta(\tilde{u}-c(\hat{a})-\bar{u})(\Delta E R) \geq \Delta c \quad \Leftrightarrow \quad \eta \geq \frac{\Delta c}{(\tilde{u}-c(\hat{a})-\bar{u})(\Delta E R)} .
$$

The right hand side is finite, hence for sufficiently large, but finite, $\eta$ the flat wage $\tilde{u}$ implements $\hat{a}$ for strictly lower cost to the principal. Therefore the optimal positive-rent contract will have strictly lower cost than the optimal zero-rent contract (i.e. the standard contract), hence the optimal contract will be a reciprocity contract.

Having demonstrated that there is an open set of parameters such that a reciprocity contract is optimal, we can proceed to describe its characteristics. Indeed, the reciprocity contract is sufficiently tractable that we can describe a number of its features, and even explicitly solve for the optimal contract for two general classes of utility functions.

Proposition 3 For $\eta>\eta^{*}$, the optimal contract has the following property, for $i>j$ :

$$
\frac{u^{\prime}\left(w_{j}\right)}{u^{\prime}\left(w_{i}\right)}=\frac{1-\frac{\pi_{i}\left(a_{1}\right)}{\pi_{i}(\hat{a})}+\eta \Delta E R}{1-\frac{\pi_{j}\left(a_{1}\right)}{\pi_{j}(\hat{a})}+\eta \Delta E R} .
$$

Proof. We solve for the optimal contract by setting $\lambda_{I R}=0$ (since we know that for $\eta>\eta^{*}$ the $[\mathrm{IR}]$ will be satisfied and slack). Therefore the FOC is $\frac{1}{u^{\prime}\left(w_{i}\right)}=\lambda_{I C}\left(1-\frac{\pi_{i}\left(a_{1}\right)}{\pi_{i}(\hat{a})}+\eta \Delta E R\right)$. If we take the ratio of any two FOC's, $\lambda_{I C}$ cancels and we get $\frac{u^{\prime}\left(w_{j}\right)}{u^{\prime}\left(w_{i}\right)}=\frac{1-\frac{\pi_{i}\left(a_{1}\right)}{\pi_{i}(\hat{a})}+\eta \Delta E R}{1-\frac{\pi_{j}\left(a_{1}\right)}{\pi_{j}(\hat{a})}+\eta \Delta E R}$. Hence the ratio of the marginal utilities between two states, and thus the incentive intensity, depends on the ratio of their likelihood ratios as well as a constant denoting the marginal impact on reciprocity of increasing the rent.

In the Appendices 5.2 and 5.3 we derive the exact form of the optimal contract for the classes of CRRA and CARA utility, respectively. Additionally, we will refer to the cases of CRRA and CARA utility specifically in the comparative statics sections below as the results there are very easily interpretable in terms of wage ratios and wage differences instead of the somewhat abstract marginal utilities ratios in the general case. 
Since we can identify features of the optimal contract without solving explicitly for $\lambda_{I C}$, we can derive general results for the optimal contract. Our guiding intuition is that the principal is mixing optimally between two incentive mechanisms - explicit monetary incentives (which depend on the wage spread across states, but not the wage level) and reciprocal incentives (which depend on the overall wage level, but not directly on the spread). Therefore, we would expect that as one incentive mechanism becomes more cost-efficient, the principal should use it relatively more.

\subsection{Comparative Statics: Reciprocity}

We should expect that as the agent gets more reciprocal, and thus it takes a smaller rent to induce any given effort, the principal should use reciprocal incentives more relative to explicit incentives. Indeed, we find that as the agent becomes more reciprocal, the optimal contract gets flatter between states, in marginal utilities (for the general optimal contract) and therefore also in wage levels (for CRRA and CARA utility).

Proposition 4 1. For $\eta>\eta^{*}$, in the optimal contract $\frac{u^{\prime}\left(w_{j}\right)}{u^{\prime}\left(w_{i}\right)}$ is decreasing in $\eta$ for all $(i, j)$ where $i>j$, with $\lim _{\eta \rightarrow \infty} \frac{u^{\prime}\left(w_{j}\right)}{u^{\prime}\left(w_{i}\right)}=1$

2. For CRRA utility, $\frac{w_{i}}{w_{j}}$ is decreasing in $\eta$, with $\lim _{\eta \rightarrow \infty} \frac{w_{i}}{w_{j}}=1$

3. For CARA utility, $\left(w_{i}-w_{j}\right)$ is decreasing in $\eta$, with $\lim _{\eta \rightarrow \infty} w_{i}-w_{j}=0$

Proof. 1. We can simply take the derivative of the marginal utility ratios, since they do not depend on $\lambda_{I C}$ :

$$
\begin{aligned}
\frac{\partial}{\partial \eta}\left[\frac{u^{\prime}\left(w_{j}\right)}{u^{\prime}\left(w_{i}\right)}\right]=\frac{\partial}{\partial \eta}\left[\frac{1-\frac{\pi_{i}\left(a_{1}\right)}{\pi_{i}(\hat{a})}+\eta \Delta E R}{1-\frac{\pi_{j}\left(a_{1}\right)}{\pi_{j}(\hat{a})}+\eta \Delta E R}\right] & =\frac{\left(\left(1-\frac{\pi_{i}\left(a_{1}\right)}{\pi_{i}(\hat{a})}\right)-\left(1-\frac{\pi_{j}\left(a_{1}\right)}{\pi_{j}(\hat{a})}\right)\right) \Delta E R}{\left(1-\frac{\pi_{j}\left(a_{1}\right)}{\pi_{j}(\hat{a})}+\eta \Delta E R\right)^{2}} \\
& =\frac{\left(\frac{\pi_{j}\left(a_{1}\right)}{\pi_{j}(\hat{a})}-\frac{\pi_{i}\left(a_{1}\right)}{\pi_{i}(\hat{a})}\right) \Delta E R}{\left(1-\frac{\pi_{j}\left(a_{1}\right)}{\pi_{j}(\hat{a})}+\eta \Delta E R\right)^{2}}>0
\end{aligned}
$$

where the sign of the expression is solely determined by $\left(\frac{\pi_{j}\left(a_{1}\right)}{\pi_{j}(\hat{a})}-\frac{\pi_{i}\left(a_{1}\right)}{\pi_{i}(\hat{a})}\right)$ which is positive by MLRP. The limit claim follows directly from l'Hôpital's rule.

2. For CRRA $\frac{u^{\prime}\left(w_{j}\right)}{u^{\prime}\left(w_{i}\right)}=\frac{\left(w_{j}\right)^{-\gamma}}{\left(w_{i}\right)^{-\gamma}}=\left(\frac{w_{i}}{w_{j}}\right)^{\gamma}$, hence $\frac{u^{\prime}\left(w_{j}\right)}{u^{\prime}\left(w_{i}\right)} \geq \frac{u^{\prime}\left(x_{j}\right)}{u^{\prime}\left(x_{i}\right)}$ iff $\frac{w_{i}}{w_{j}} \geq \frac{x_{i}}{x_{j}}$. Therefore the first claim implies the second claim for CRRA utility. 
3. For CARA $\frac{u^{\prime}\left(w_{j}\right)}{u^{\prime}\left(w_{i}\right)}=\frac{\exp \left(-\alpha w_{j}\right)}{\exp \left(-\alpha w_{i}\right)}=\exp \left(\alpha\left(w_{i}-w_{j}\right)\right)$, hence $\frac{u^{\prime}\left(w_{j}\right)}{u^{\prime}\left(w_{i}\right)} \geq \frac{u^{\prime}\left(x_{j}\right)}{u^{\prime}\left(x_{i}\right)}$ iff $\left(w_{i}-w_{j}\right) \geq$ $\left(x_{i}-x_{j}\right)$. Therefore the first claim implies the third claim for CARA utility.

Since the rent needed to induce effort gets smaller as the agent gets more reciprocal, the cost of reciprocal incentives decreases. Therefore in the optimal contract the principal substitutes away from explicit incentives (since they are now relatively more expensive compared to reciprocal incentives).

We can also directly prove that increasing the value of the agent's effort similarly leads to weaker incentives. Thus, making the return "gift" of effort more valuable to the principal (for the same cost of effort) increases the agent's willingness to work hard in exactly the same way as making him intrinsically more reciprocal.

Corollary 2 1. For $\eta>\eta^{*}, \frac{u^{\prime}\left(w_{j}\right)}{u^{\prime}\left(w_{i}\right)}$ is decreasing in $\Delta E R$, with $\lim _{\Delta E R \rightarrow \infty} \frac{u^{\prime}\left(w_{j}\right)}{u^{\prime}\left(w_{i}\right)}=1$

2. For CRRA utility, $\frac{w_{i}}{w_{j}}$ is decreasing in $\Delta E R$, with $\lim _{\Delta E R \rightarrow \infty} \frac{w_{i}}{w_{j}}=1$

3. For CARA utility, $w_{i}-w_{j}$ is decreasing in $\Delta E R$, with $\lim _{\Delta E R \rightarrow \infty} w_{i}-w_{j}=0$

Proof. Note that in the above equations, $\eta$ always appears as $\eta \Delta E R$, hence an increase in $\triangle E R$ is equivalent to an increase in $\eta$.

\subsection{Comparative Statics: Information}

We can also demonstrate that when output is a more informative signal of effort, contracts use more explicit incentives. We are unaware of any other papers in the literature that are able to examine directly the strength of incentives between states as the information structure changes. We begin by developing some notation to allow us to compare the incentives of two contracts.

Let $w$ and $x$ be two contracts specifying wage payments in states $i=1, \ldots, n$.

Definition 1 Define the partial order over contracts $w \succ_{m u} x$, "w implies sharper marginal utilities in the extremes than $x$ " if $\exists i^{\prime} \geq \tilde{i}>\tilde{j} \geq j^{\prime}$ s.t. $\frac{u^{\prime}\left(w_{j}\right)}{u^{\prime}\left(w_{i}\right)} \geq \frac{u^{\prime}\left(x_{j}\right)}{u^{\prime}\left(x_{i}\right)} \forall i \geq \tilde{i}, j \leq \tilde{j}$ with strictness for all $\left(i^{\prime}, j\right)$ and $\left(i, j^{\prime}\right)$.

This relation requires that for some set of "high" states and some set of "low" states, the ratio of marginal utilities for any high state and any low state is higher in $w$ than in $x$, and strict for at least one high state and one low state. Thus the "sharper" contract provides 
greater rewards for achieving high output states relative to low output states. For example increasing the bonus size for a step-function bonus, or increasing the commission rate for a commission with a sales-hurdle makes the monetary incentives "sharper".

Note that $\succ_{m u}$ is transitive, if $w \succ_{m u} x$ for $\left(\tilde{i_{1}}, \tilde{j_{1}}\right)$ and $x \succ_{m u} y$ for $\left(\tilde{i_{2}}, \tilde{j_{2}}\right)$, then $w \succ_{m u} y$ for $(\tilde{i}, \tilde{j})=\left(\max \left[\tilde{i_{1}}, \tilde{i_{2}}\right], \min \left[\tilde{j}_{1}, \tilde{j}_{2}\right]\right)$, where there will be strictness for $i^{\prime}=\max \left[i_{1}^{\prime}, i_{2}^{\prime}\right]$ and $j^{\prime}=\min \left[j_{1}^{\prime}, j_{2}^{\prime}\right]$. Note also that if $w \succ_{m u} x$ for some $\left(i_{1}^{\prime}, \tilde{i}_{1}, \tilde{j}_{1}, j_{1}^{\prime}\right)$ then you cannot have $w \succ_{m u} x$ for some other $\left(i_{2}^{\prime}, \tilde{i_{2}}, \tilde{j_{2}}, j_{2}^{\prime}\right)$.

Assume without loss of generality that $\tilde{i_{1}} \geq \tilde{i_{2}}$. Then $w \succ_{m u} x$ implies $\frac{u^{\prime}\left(w_{1}\right)}{u^{\prime}\left(w_{i 1}\right)}>\frac{u^{\prime}\left(x_{1}\right)}{u^{\prime}\left(x_{i 1}\right)}$, while $x \succ_{m u} w$ implies $\frac{u^{\prime}\left(w_{1}\right)}{u^{\prime}\left(w_{i 1}\right)} \leq \frac{u^{\prime}\left(x_{1}\right)}{u^{\prime}\left(x_{i 1}\right)}$, a contradiction.

In some cases we will be able to make stronger comparisons between contracts, such that every state is either a high state or a low state.

Definition 2 Define the partial order $w \succ_{m u, \tilde{k}} x$, " $w$ has sharper marginal utilities about state $\tilde{k}$ than $x "$ if $w \succ_{m u} x$ for $\tilde{i}=\tilde{k}$ and $\tilde{j}=\tilde{i}-1$. Again, note that $\succ_{\text {mu, } \tilde{k}}$ is transitive holding $\tilde{k}$ fixed.

As with the previous comparative static, for CRRA and CARA utilities the general relation for marginal utilities will imply a relation for ratio and difference (respectively) of wage levels: "sharper" contracts give a larger increase in wages between low output states and high output states.

Definition 3 Define the partial order over contracts $w \succ_{w r} x$, " $w$ has sharper wage ratios in the extremes than $x "$ if $\exists i^{\prime} \geq \tilde{i}>\tilde{j} \geq j^{\prime}$ s.t. $\frac{w_{i}}{w_{j}} \geq \frac{x_{i}}{x_{j}} \forall i \geq \tilde{i} ; j \leq \tilde{j}$ with strictness for all $\left(i^{\prime}, j\right)$ and $\left(i, j^{\prime}\right)$.

Definition 4 Define the partial order $w \succ_{w r, \tilde{k}} x$,' $w$ has sharper wage ratios about state $\tilde{k}$ than $x^{\prime}$ if $w \succ_{\text {wr }} x$ for $\tilde{i}=\tilde{k}$ and $\tilde{j}=\tilde{i}-1$.

Definition 5 Define the partial order over contracts $w \succ_{w d} x$,' 'w has sharper wage differences in the extremes than $x^{\prime}$ if $\exists i^{\prime} \geq \tilde{i}>\tilde{j} \geq j^{\prime}$ s.t. $w_{i}-w_{j} \geq x_{i}-x_{j} \forall i \geq \tilde{i} ; j \leq \tilde{j}$ with strictness for all $\left(i^{\prime}, j\right)$ and $\left(i, j^{\prime}\right)$.

Definition 6 Define the partial order $w \succ_{w d, \tilde{k}} x$, 'w has sharper wage differences about state $\tilde{k}$ than $x^{\prime}$ if $w \succ_{w d} x$ for $\tilde{i}=\tilde{k}$ and $\tilde{j}=\tilde{i}-1$.

Lemma 3 If $u(\cdot)$ is CRRA then $\succ_{m u}$ and $\succ_{w r}$ are equivalent. If $u(\cdot)$ is CARA then $\succ_{m u}$ and $\succ_{w d}$ are equivalent. 
Proof. For CRRA $\frac{u^{\prime}\left(w_{j}\right)}{u^{\prime}\left(w_{i}\right)}=\frac{\left(w_{j}\right)^{-\gamma}}{\left(w_{i}\right)^{-\gamma}}=\left(\frac{w_{i}}{w_{j}}\right)^{\gamma}$, hence $\frac{u^{\prime}\left(w_{j}\right)}{u^{\prime}\left(w_{i}\right)}=\geq \frac{u^{\prime}\left(x_{j}\right)}{u^{\prime}\left(x_{i}\right)}$ iff $\frac{w_{i}}{w_{j}} \geq \frac{x_{i}}{x_{j}}$.

For CARA $\frac{u^{\prime}\left(w_{j}\right)}{u^{\prime}\left(w_{i}\right)}=\frac{\exp \left(-\alpha w_{j}\right)}{\exp \left(-\alpha w_{i}\right)}=\exp \left(\alpha\left(w_{i}-w_{j}\right)\right)$, hence $\frac{u^{\prime}\left(w_{j}\right)}{u^{\prime}\left(w_{i}\right)}=\geq \frac{u^{\prime}\left(x_{j}\right)}{u^{\prime}\left(x_{i}\right)}$ iff $\left(w_{i}-w_{j}\right) \geq$ $\left(x_{i}-x_{j}\right)$.

Having developed a concept to compare incentive intensity across contracts, we also need to specify in what sense the principal's information "improves". We focus on the standard comparison in the literature: that the likelihood ratios of one information structure are a mean preserving spread of the other information structure. ${ }^{13}$

Let $\Pi^{F}$ and $\Pi^{G}$ be two discrete probability distributions over the states, where the likelihood ratios for implementing $\hat{a}$ are distributed according to $F$ and $G$ respectively.

From Kim (1995) $G$ is a mean preserving spread of $F$ if $F$ and $G$ have the same means and $\int^{y} G(t) d t \geq \int^{y} F(t) d t$ for all $y \in \Re$ and strict for some range with positive measure.

For $z_{k}=\left\{z \mid z \quad\right.$ is a likelihood ratio of either $\Pi^{F}$ or $\left.\Pi^{G}\right\}$

$$
f_{k}=\operatorname{Pr}\left[1-\frac{\pi_{j}^{F}}{\hat{\pi}_{j}^{F}}=z_{k}\right] \text { and } g_{k}=\operatorname{Pr}\left[1-\frac{\pi_{j}^{G}}{\hat{\pi}_{j}^{G}}=z_{k}\right] \text {. }
$$

From Rothschild-Stiglitz (1970), we can focus on the step function $S(x)=G(x)-F(x)$, and the corresponding step function $s\left(z_{k}\right)=g_{k}-f_{k}$.

Additionally, if we restrict attention to a specific class of mean-preserving spreads, we will be able to make stronger comparisons between contracts.

Definition $7 G$ differs from $F$ via a balanced $\boldsymbol{M P S}$ if $\exists \breve{x}$ s.t. $S(x) \geq 0$ for $x<\breve{x}$ and $S(x) \leq 0$ for $x>\breve{x}$. Let $\breve{i}$ be the highest state with a likelihood ratio less than or equal to $\breve{x}$.

Hence in a balanced MPS, the likelihood ratios for all states with a likelihood ratio smaller than $\breve{x}$ do not increase, while the likelihood ratios for all the states with a likelihood ratio larger than $\breve{x}$ do not decrease. Increasing the variance of a normal distribution is an example of a balanced MPS.

Additionally, we will want to break apart the difference in the distributions into a number of individual changes. From Rothschild and Stiglitz (1970), we say $G$ differs from $F$ by a single MPS if $g_{k}=f_{k}$ except for four states (denoted 1 to 4 for simplicity with $z_{1}<z_{2}<$ $\left.z_{3}<z_{4}\right)$ and $g_{1}-f_{1}=-\left(g_{2}-f_{2}\right) \geq 0, g_{4}-f_{4}=-\left(g_{3}-f_{3}\right) \geq 0$ and $\sum_{k=1}^{4} z_{k}\left(g_{k}-f_{k}\right)=0$ Let $\underline{\delta}=z_{2}-z_{1}$ and $\bar{\delta}=z_{4}-z_{3}$ (i.e. the change in the likelihood ratios).

\footnotetext{
${ }^{13}$ Cf. eg. Kim (1995).
} 
For these simple changes in information, we can easily show that, if both optimal contracts are reciprocity contracts, the contract under the better information structure will be sharper in marginal utilities in the extremes.

Lemma 4 If $G$ differs from $F$ by only a single $M P S, w^{*}(G), x^{*}(F)$ are the optimal contracts given the distribution of likelihood ratios, and $\eta \geq \max \left[\eta^{*}(F), \eta^{*}(G)\right]$ then $w^{*}(G) \succ_{m u} x^{*}(F)$.

Proof. See Appendix 5.4

Using the Rothschild-Stiglitz result that an MPS can be deconstructed into a sequence of single MPS's, we can show that

Proposition 5 If $G$ is an MPS of $F, w^{*}(G), x^{*}(F)$ are the optimal contracts given the distribution of likelihood ratios, and $\eta \geq \max \left[\eta^{*}(F), \eta^{*}(G)\right]$ then $w^{*}(G) \succ_{m u} x^{*}(F)$. Additionally, if $G$ is a balanced MPS of $F$, then $w^{*}(G) \succ_{m u, \breve{i}} x^{*}(F)$.

Proof. See Appendix 5.5

As output becomes a more informative signal about effort this means that the agent taking the high effort action makes it increasingly more likely that a high output state is obtained rather than a low output state. The optimal contract exploits this by increasing the (relative) reward in high states and decreasing the (relative) reward in low states, i.e. the optimal contract provides "sharper" monetary incentives. For the cases of CRRA and CARA utility, the corresponding results for wage ratios and wage differences follow immediately.

Corollary 3 If $G$ is an MPS of $F$ and $w^{*}(G), x^{*}(F)$ are both reciprocity contracts, then $w^{*}(G) \succ_{w r} x^{*}(F)$ if $u(\cdot)$ is CRRA and $w^{*}(G) \succ_{w d} x^{*}(F)$ if $u(\cdot)$ is CARA. Additionally, if $G$ is a balanced MPS of $F$, then $w^{*}(G) \succ_{w r, \breve{i}} x^{*}$ if $u(\cdot)$ is $C R R A$ and $w^{*}(G) \succ_{w d, \breve{i}} x^{*}(F)$ if $u(\cdot)$ is $C A R A$.

\section{Proof. Apply Lemma 3.}

Thus as the output realization becomes a better signal of effort, the optimal contract uses more explicit incentives, in the sense of larger changes in either marginal utility or wages between low output and high output states. 


\subsection{Multiple Action Case}

In Appendix 5.6 we show how our results extend to the case of multiple action levels for the agent. We show that without any further distributional assumptions Observations 1 through 4 directly extend to the multiple action case. We can also show that the principal's value function is non-increasing in $\eta$, that a downward [IC] always binds and hence the principal does not provide excessive incentives, and that for sufficiently high values of $\eta$ a reciprocity contract is indeed the optimal contract. Furthermore we show that if we assume CDFC, introduced by Rogerson (1985), all our results, including the comparative statics, extend to the multi action case.

\section{The Extended Model}

\subsection{A Model of Organizational Structure}

A problem with most of the behavioral contracting models (and with optimal contracting models more generally), is a relative scarcity of empirically falsifiable predictions. Results depend on hard to observe variables (preference parameters, stochastic properties of the problem, costs to monitor, ...) and not even data on all predictions (incentive intensity, details of the contract, ... ) are readily accessible to the researcher.

Our basic model is not different in this respect. Results also depend on hard to observe parameters like $\eta$, the effect of agent's effort on the principal's payoff, or the stochastic properties of the problem. However, our model can be extended to allow us to make predictions about properties of organizational structure. Our baseline model assumes that either the principal is a single individual, or if the principal is a firm that the agent feels reciprocal to the firm as a whole. However, rather than treating the firm as a monolith, the agent could have different reciprocal feelings towards particular individuals on the firm side. In particular it seems reasonable to suppose that an individual may give more "credit" for kindness to the particular manager that sets his pay. Moreover, Coffman and Bazerman (2008) find that individuals place the majority of the blame for unkind actions on the specific individual who ultimately made the decision, even when the previous actions of another person restricted his choice set. If the agent feels more reciprocal towards particular individuals within the firm, then the compensation setting and decision making features of the organization will affect the impact of reciprocal sentiments. If the firm decides to make use of reciprocal 
incentives, specific properties of the organizational structure like the allocation of decision rights over pay ("who gives the gift") or the use of performance pay across the hierarchy can be adjusted to give reciprocal incentives the most leverage.

To see this, consider the following stylized model. There are two risk neutral managers, $I$ and $I I$, whose payoffs are (different) monotonic functions of firm revenue $\left(f_{I}(E R)\right.$ and $f_{I I}(E R)$ respectively). For simplicity we assume that only one manager takes an action that is payoff relevant to the agent, and that the agent gives all of the "credit" for rent he receives to the manager who took the action ${ }^{14}$. Since we are focusing on the agency problem of the reciprocal agent, we assume that whichever manager takes an action will set the agent's contract to maximize overall firm profit. In particular, we will consider three simple organizational relationships between $I$ and $I I$ to illustrate the role of managerial compensation and decision-making for the reciprocity of subordinates:

- $I$ is the firm owner and $I I$ a manager. The manager determines the agent's contract, while the owner takes no action. We then vary the strength of the manager's incentives.

- $I$ and $I I$ are managers of different agents (who work independently). Each manager determines the contract for his agent. We then vary whether the managers' incentives are narrow (depending only on the revenue generated by their agent) or broad (depending on the total revenue).

- $I$ is the agent's direct supervisor (whose compensation is highly dependant on the agent's output) and $I I$ is a senior manager (whose compensation is weakly dependent on the agent's output). We consider the effect of having the agent's pay set centrally (by $I I$ ) versus giving the supervisor discretion over pay (i.e. $I$ sets the contract).

Let $\quad D_{k}=1$ if manager $\mathrm{k}$ determines the agent's contract, for $k \in\{I, I I\}$

$$
=0 \text { otherwise }
$$

Furthermore we assume that the agent's preference intensity for reciprocity is person-independent, i.e. $\eta$ is constant for managers $I$ and $I I$. Then we can write the agent's preferences as follows:

$$
\begin{aligned}
U(a, \hat{a})=\sum \pi_{i}(a) u_{i}-c(a) & +\eta\left[D_{I} *\left(\sum \pi_{i}(\hat{a}) u_{i}-c(\hat{a}) \bar{u}\right)\right]\left(f_{I}(\operatorname{ER}(a))\right) \\
& +\eta\left[D_{I I} *\left(\sum \pi_{i}(\hat{a}) u_{i}-c(\hat{a}) \bar{u}\right)\right]\left(f_{I I}(E R(a))\right) .
\end{aligned}
$$

\footnotetext{
${ }^{14}$ It would be sufficient to generate the following results to instead assume that the decision of one manager has a larger impact on the agent's payoff than the other manager, and that the agent assigns a larger fraction of the perceived kindness to the manager whose action was relatively more important. The simpler model we consider in the text is the limit version of this assumption.
} 
For simplicity we focus on the two action case where $\eta>\eta^{*}$, i.e. a reciprocity contract is optimal. We also abstract away from agency problems at the managerial level; we assume that all managers set the agent's pay optimally with respect to the firm's overall objective function.

\subsubsection{Strength of Managerial Incentives}

We first consider the case where principal $I$ is the owner of the firm and principal $I I$ is the manager. We assume that the manager sets the agent's pay while the owner takes no action (i.e. $D_{I}=0$ and $D_{I I}=1$ ). To have a simple metric for the strength of the manager's incentives, we assume that the owner and the manager split the revenue via a linear compensation scheme:

$$
f_{I I}(E R)=\alpha+\beta * E R(a) \quad f_{I}(E R)=(1-\beta) * E R(a)-\alpha
$$

Hence the manager will have stronger incentives when $\beta$ is larger. It is straightforward to show that reciprocity will have a stronger incentive effect for the agent when $\beta$ is larger, and therefore the costs of agency will be smaller. Let $V(\eta, \beta)$ denote the value function at the optimum of the principal's problem given the manager's incentives.

Proposition 6 For a given $\eta>\eta^{*}(\beta), V(\eta, \beta)$ is decreasing in $\beta$.

Proof. Since $D_{I}=0$, the reciprocity terms relating to the owner drop out of the agent's utility. Therefore, this model is isomorphic to the base model, replacing $E R(a)$ with $\alpha+$ $\beta * E R(a)$, and therefore replacing $\Delta E R$ with $\beta * \Delta E R$. Note that $\alpha$ cancels - the agent only cares about the change in the manager's payoff due to effort, not the absolute level. Therefore increasing $\beta$ is equivalent to increasing $\Delta E R$, and thus the set of implementable contracts increase (since reciprocal incentives are stronger) and therefore the costs of agency decrease. This holds even if $\alpha$ depends on $\beta$, since $V$ is invariant to $\alpha$.

Additionally, the comparative static for reciprocity also extends.

Corollary 4 1. For $\eta>\eta^{*}(\beta), \frac{u^{\prime}\left(w_{j}\right)}{u^{\prime}\left(w_{i}\right)}$ is decreasing in $\beta$ for all $i>j$.

2. For CRRA utility, $\frac{w_{i}}{w_{j}}$ is decreasing in $\beta$ for all $i>j$.

3. For CARA utility, $w_{i}-w_{j}$ is decreasing in $\beta$ for all $i>j$. 
Since the manager is the only principal that factors into the agent's reciprocity, increasing the strength of his incentives makes the agent's effort more valuable to him, and therefore for any amount of rent the agent is more willing to exert effort. Thus at the optimum the agent's explicit monetary incentives will be weaker when the manager's incentives are stronger.

\subsubsection{Breadth of Managerial Incentives}

We now consider the case where managers $I$ and $I I$ are division managers - each oversees an agent who works independently and generates separate output $E R_{I}$ and $E R_{I I}$. We assume the two agents are identical. Each manager determines the contract for his agent. We consider two kinds of incentives for the managers: narrow incentives where each manager is compensated for the output of his worker, and broad incentives where both managers are compensated for the total output of both workers.

Case 1 (Broad incentives) $f_{k}\left(E R_{I}, E R_{I I}\right)=\frac{E R_{I}+E R_{I I}}{2}$

Case 2 (Narrow incentives) $f_{k}\left(E R_{I}, E R_{I I}\right)=E R_{k}$.

Since the agents' outputs are independent we focus without loss of generality on the agency problem for agent $I I$. For this agent we then have that manager $I I$ is the only manager who makes a payoff-relevant decision (i.e. $D_{I}=0$ and $D_{I I}=1$ ). Therefore the reciprocity term for manager $I$ drops out of the agent's utility function. Thus, broadening managerial incentives decreases the impact that high effort will have on the payoff of the manager that the agent feels reciprocal towards. Therefore, the reciprocal sentiments of the agent will have greatest impact when managerial incentives are narrow. Let $V_{i}(\eta)$ denote the value function of the principal's problem in Case 1.

Proposition 7 For a given $\eta>\max \left(\eta_{1}^{*}, \eta_{2}^{*}\right)$ and for any contract for the other agent, $V_{1}(\eta)>V_{2}(\eta)$

Proof. Let $E R_{I}\left(\hat{a}_{I}\right)$ denote the expected revenue given the action of agent $I$. Then Case 2 is equivalent to setting $\alpha=0$ and $\beta=1$ in the previous model, while Case 1 is equivalent to setting $\alpha=\frac{E R_{I}\left(\hat{a}_{I}\right)}{2}$ and $\beta=\frac{1}{2}$. Since $V$ is decreasing in $\beta$, the result follows immediately.

Since broader incentives are less responsive to the agent's effort, the agent is less able to return the principal's kindness when he has broad incentives. Therefore, reciprocal incentives are less effective. Similarly, the optimal monetary incentives for the agent will be weaker when the manager's incentives are narrower. 
Corollary 5 1. For $\eta>\max \left(\eta_{1}^{*}, \eta_{2}^{*}\right), \frac{u^{\prime}\left(w_{j}\right)}{u^{\prime}\left(w_{i}\right)}$ is smaller in Case 2 than in Case 1 for all $i>j$.

2. For CRRA utility, $\frac{w_{i}}{w_{j}}$ is smaller in Case 2 than in Case 1 for all $i>j$.

3. For CARA utility, $w_{i}-w_{j}$ is smaller in Case 2 than in Case 1 for all $i>j$.

\subsubsection{Managerial Discretion}

Lastly, we consider the role of the decision rights over the agent's pay. To that end we compare the case where the agent's compensation is determined centrally by a senior manager $I$ (e.g. by the HR department, by a firm wide compensation policy, etc.) or where the agent's supervisor II has discretion over the agent's pay. To capture this difference we distinguish $I$ and $I I$ by the responsiveness of their payoffs to this agent's output. We assume that the supervisor's payoffs are relatively more sensitive to an increase in output than the senior manager who is further away in the hierarchy of the firm. That is, we assume

$$
f_{I I}(E R(\hat{a}))-f_{I I}\left(E R\left(a_{1}\right)\right)>f_{I}(E R(\hat{a}))-f_{I}\left(E R\left(a_{1}\right)\right)
$$

We now consider two cases:

Case 1 (Central Policy) Manager I determines the agent's contract, while manager II takes no action.

Case 2 (Managerial Discretion) Manager II determines the agent's contract, while manager $I$ takes no action.

Since the payoffs of manager $I$ are affected less when the agent works hard than the payoffs of manager $I I$, it is straightforward to show that reciprocity will be more effective as an incentive for the agent when manager $I I$ sets his pay (and thus gets credit for any rents).

Proposition 8 For a given $\eta>\max \left(\eta_{1}^{*}, \eta_{2}^{*}\right), V_{1}(\eta)>V_{2}(\eta)$.

Proof. In each case, the reciprocity terms for the manager who doesn't make a decision drop out of the agent's utility function, therefore each Case $\mathrm{k}$ is isomorphic to the base model, replacing $\Delta E R$ with $f_{k}(E R(\hat{a}))-f_{k}\left(E R\left(a_{1}\right)\right)$. Thus the results from the base case immediately imply the result, since $\Delta E R_{I I}>\Delta E R_{I}$.

Again, this also implies that the optimal monetary incentives will be weaker in Case 2 than in Case 1. 
Corollary 6 1. For $\eta>\max \left(\eta_{1}^{*}, \eta_{2}^{*}\right), \frac{u^{\prime}\left(w_{j}\right)}{u^{\prime}\left(w_{i}\right)}$ is smaller in Case 2 than in Case 1 for all $i>j$.

2. For CRRA utility, $\frac{w_{i}}{w_{j}}$ is smaller in Case 2 than in Case 1 for all $i>j$.

3. For CARA utility, $w_{i}-w_{j}$ is smaller in Case 2 than in Case 1 for all $i>j$.

These results indicate that the organizational features of the firm can significantly influence the effectiveness of reciprocity as an incentive device. Taken together they suggest that reciprocity will be most effective when the manager who has decision rights over the compensation for the agent also has strong, narrow incentives related to the agent's productivity.

\subsection{The WERS Data Set}

In order to test the predictions from the extended model we use the 1998 Workplace Employee Relations Survey (WERS 98), the fourth in a government-funded series of surveys carried out at British workplaces. The WERS 98 has very detailed information on work practices and organizational structure in 2191 UK workplaces in manufacturing industries with at least 10 employees. The mean workplace size is 212 with a maximum size of 14135 . $19 \%$ of the establishments are part of the production sector. The survey covers a wide range of firms with respect to their competitive situation. While $33 \%$ have a UK market share for their main product or service of less than $5 \%$ there are also about $15 \%$ who have a UK market share of more than $50 \%$.

The WERS is particularly apt for our purposes as it has information on the use and scope of incentives throughout a firm's hierarchy and on whether or not a firm uses personality tests (in addition to or instead of ability tests) in the hiring process. ${ }^{15}$ We interpret the use of personality tests as a proxy for firms screening for reciprocal workers, or more generally that the firm is likely to obtain a highly reciprocal workforce while screening for other (correlated) traits. Our empirical approach is consistent with the results from Ashton et al (1997), Ben-Ner et al (2004), and Englmaier and Leider (2008), who show that personality traits that are usually identified with personality tests like the "Big 5 Test" are closely correlated with reciprocity as commonly defined in laboratory experiments. Autor and Scarborough (forthcoming) document the hiring procedures of a large retail firm, which according to the authors are representative for the industry, that uses personality tests to

\footnotetext{
${ }^{15}$ While $59 \%$ of firms use performance or competency test, only $34 \%$ use personality or attitude tests when filling vacancies.
} 
screen workers upon hiring. The firm gave hiring preference to applicants with positive z-scores for "agreeableness", "conscientiousness", and "extroversion", Big 5 traits that are predictive for the presence of reciprocity. Hence we assume that firms that use personality tests in their hiring procedures are more likely to hire reciprocal employees and thus make use of reciprocal incentives in their personnel policy. Thus their organizational structure should be more likely to be coordinated to maximize the efficiency of reciprocal incentives. With these firms as our main focus, we can examine the following hypotheses.

Hypothesis 1 If a firm uses personality tests wages should be, ceteris paribus, higher.

This is a direct implication of our base model. If a firm wants to use reciprocal incentives it has to leave a rent to the worker by paying more generous wages. While other factors may be correlated with both using personality tests and granting higher wages, above-market pay for workers is a necessary starting point for the reciprocity mechanism to generate our more specific predictions.

Hypothesis 2 If a firm uses personality tests and managers have incentive pay, then nonmanagers are less likely to have incentive pay.

For the interpretation of this hypotheses it is important to note that the use of personality tests and particularly the use of incentive pay for both managers and non-managers is likely to be positively correlated. Both are features of a sophisticated human resource policy. Once a firm pays a fixed cost to have a specialized HR department in place, the use of personality tests upon hiring becomes easier to implement. A high quality HR department will also ease the design and implementation of performance based pay systems. Similarly, there is a large fixed cost to establishing a monitoring and control system in order to provide managers with performance-based incentive pay. If such a monitoring and control system is in place, it should become relatively cheap to extend performance pay to non-managers. In order to get beyond this (expected) "technical" positive correlation our analysis will focus on the interaction effect of Personality Test $\times$ Managers Have Variable Pay in order to isolate the additional effect of using these complementary channels to improve the effectiveness of reciprocal incentives, rather than the overall net probability of using incentive pay. While we might expect personality tests, managerial incentive pay and non-managerial incentive pay to be technological complements, our model of reciprocity predicts that personality tests and managerial pay should in fact be (jointly) substitutes for non-managerial pay. That is when firms have sufficiently reciprocal workers and have managerial pay schemes that allow for workers to reciprocate to their managers via hard work, firms should be less likely 
to choose to provide monetary incentives to workers, since reciprocal motivations may be sufficient. This prediction is in fact quite a conservative test of the model due to limitations in the data. We cannot observe the magnitude of monetary incentives, only their presence. Thus we cannot identify firms who choose weaker monetary incentives, which would also be consistent with the model, only those who chose zero monetary incentives. Since we can only observe the most extreme substitutions towards reciprocal incentives, we do not expect to find that the average "reciprocal" firm chooses not to use monetary incentives, merely that firms on the margin substitute away from monetary incentives.

Hypothesis 3 If a firm uses personality tests and managers have incentive pay, then managers' incentives have a more narrow scope.

When a firm has a workforce that is sufficiently reciprocal to make a reciprocity contract potentially appealing, the firm will have lower agency costs (for workers) when it makes worker reciprocity more effective by providing managers with narrower incentive pay (i.e. determined by the productivity of a smaller sub-unit within the firm). This implies that firms that screen for reciprocal employees and that allow workers to reciprocate to their supervisors by offering variable pay to managers, will also help workers to reciprocate effectively by not diluting the supervisor's payoffs by adding too broad based components to the pay package.

Hypothesis 4 If a firm uses personality tests and direct supervisors have discretion over workers' pay, then non-managers are less likely to have incentive pay.

As before, because there may be technological main effects correlating HR policies with worker incentive pay, we focus on the interaction term Personality Test $\times$ Supervisors have Decision Rights. The firms where reciprocal incentives will be most effective at providing motivation to exert effort will be firms that have both reciprocal workers and have the principal who is easiest to reciprocate towards (the direct supervisor) be the one to provide the "gift" of high wages. Thus at the margin we should expect some firms to substitute away from explicit monetary incentives for the non-managerial workers towards reciprocal incentives. As with Hypothesis 2, we can only make a very conservative test, since we can only identify firms who substitute completely away from monetary incentives. Hence we only hope to find that firms with both personality tests and supervisor decisions rights are less likely to use variable pay incentives for their workers than those characteristics would independently suggest, rather than make any prediction about the overall probability.

To check Hypothesis 1 refer to Table 1 where we run an Ordered Probit on the probability of falling in a certain pay category. As predicted the explanatory variable Use Personality 
Test at Hiring is highly significantly positive, indicating that firms that use personality test upon hiring indeed pay higher wages. In the regression we control for various other variables and a large number of dummies, notably for firm size. We also control for the use of performance pay, such that the higher wages associated with personality tests cannot be attributed to a risk premium paid to the workers to compensate them for steep incentives. However, as this is our least specific prediction we do not view this as a particularly strong test of our model, however we find it reassuring to find this basic effect.

\begin{tabular}{|c|c|}
\hline \multicolumn{2}{|l|}{ Non-Manager Wages } \\
\hline COEFFICIENT & $(1)$ \\
\hline Use Personality Test at Hiring (by Job Type) & $\begin{array}{l}0.221^{* * *} \\
(0.048)\end{array}$ \\
\hline Use Competency Test at Hiring (by Job Type) & $\begin{array}{l}0.0699^{* * *} \\
(0.025)\end{array}$ \\
\hline Use Profit-based Pay (by Job Type) & $\begin{array}{l}0.000461 \\
(0.030) \\
\end{array}$ \\
\hline Use Performance-based Pay (by Job Type) & $\begin{array}{l}0.0570^{*} \\
(0.031)\end{array}$ \\
\hline Use Employee Stock Ownership (by Job Type) & $\begin{array}{l}-0.0355 \\
(0.034)\end{array}$ \\
\hline Employee has control over Tasks & $\begin{array}{l}0.0912^{* * *} \\
(0.024)\end{array}$ \\
\hline Employee has control over Pace & $\begin{array}{l}0.0348 \\
(0.025) \\
\end{array}$ \\
\hline Employee has control over How to Perform Work & $\begin{array}{l}0.117^{* * *} \\
(0.032)\end{array}$ \\
\hline Weekly Hours Worked & $\begin{array}{l}0.186^{* * *} \\
(0.0090) \\
\end{array}$ \\
\hline Weekly Hours Worked $^{2}$ & $\begin{array}{l}-0.00142^{* * *} \\
(0.000096)\end{array}$ \\
\hline Gender, Race, Job Type, Experience, Training, Education, Contract Type, Industry, Union, and Firm Size Dummies & YES \\
\hline \multicolumn{2}{|l|}{ Constants } \\
\hline$£ 1$ to $£ 2,600$ per year & $\begin{array}{l}1.104^{* * * *} \\
(0.21)\end{array}$ \\
\hline$£ 2,601$ to $£ 4,160$ per year & $\begin{array}{l}2.396^{* * *} \\
(0.23)\end{array}$ \\
\hline$£ 4,161$ to $£ 7,280$ per year & $\begin{array}{l}3.826^{* * *} \\
(0.25)\end{array}$ \\
\hline$£ 7,281$ to $£ 9,360$ per year & $\begin{array}{l}4.540^{* * *} \\
(0.26)\end{array}$ \\
\hline$£ 9,361$ to $£ 11,440$ per year & $\begin{array}{l}5.220 * * * \\
(0.26)\end{array}$ \\
\hline$£ 11,441$ to $£ 13,520$ per year & $\begin{array}{l}5.774^{* * *} \\
(0.26) \\
\end{array}$ \\
\hline$£ 13,521$ to $£ 16,120$ per year & $\begin{array}{l}6.310^{* * *} \\
(0.27)\end{array}$ \\
\hline$£ 16,121$ to $£ 18,720$ per year & $\begin{array}{l}6.807^{* * *} \\
(0.27) \\
\end{array}$ \\
\hline$£ 18,721$ to $£ 22,360$ per year & $\begin{array}{l}7.525^{* * *} \\
(0.27)\end{array}$ \\
\hline$£ 22,361$ to $£ 28,080$ per year & $\begin{array}{l}8.354^{* * *} \\
(0.27)\end{array}$ \\
\hline$£ 28,081$ to $£ 35,360$ per year & $\begin{array}{l}8.991^{* * *} \\
(0.27)\end{array}$ \\
\hline over $£ 35,360$ per year & $\begin{array}{l}10.74^{* * *} \\
(0.34)\end{array}$ \\
\hline Observations & 20350 \\
\hline
\end{tabular}

Table 1: WERS - Non-Manager Wages

We run an OLS regression with interactions with Use of Variable Pay for Non-Managers 
as the independent variable, defined as whether a non-managerial workers receive any sort of performance pay, and the dependent variables Use Personality Test at Hiring and Managers have Variable Pay. We control for the use of competency tests and include standard firm size, industry, union, and competition dummies. The key components of our specification are however the interactions Personality Test $\times$ Managers Have Variable Pay and Personality Test $\times$ Supervisors Have Decision Rights. The results are reported in Table 2.

\begin{tabular}{|c|c|c|c|c|c|c|}
\hline \multicolumn{7}{|c|}{ Use of Variable Pay for Non-Managers } \\
\hline COEFFICIENT & (1) & $(2)$ & (3) & $(4)$ & $(5)$ & (6) \\
\hline Managers Have Variable Pay & $\begin{array}{l}0.903^{* * *} \\
(0.022)\end{array}$ & $\begin{array}{l}0.904^{* * *} \\
(0.023)\end{array}$ & $\begin{array}{l}0.892^{* * *} \\
(0.022)\end{array}$ & $\begin{array}{l}0.888^{* * *} \\
(0.024)\end{array}$ & $\begin{array}{l}0.930 * * * \\
(0.023)\end{array}$ & $\begin{array}{l}0.935^{* * *} \\
(0.023)\end{array}$ \\
\hline Use Personality Test at Hiring & $\begin{array}{l}0.0331 \\
(0.038)\end{array}$ & $\begin{array}{l}0.0587 \\
(0.046)\end{array}$ & $\begin{array}{l}0.0315 \\
(0.030)\end{array}$ & $\begin{array}{l}0.0434 \\
(0.035)\end{array}$ & $\begin{array}{l}0.0787 \\
(0.054)\end{array}$ & $\begin{array}{l}0.116^{*} \\
(0.066)\end{array}$ \\
\hline Personality Test x Managers Have Variable Pay & $\begin{array}{l}-0.0596 \\
(0.041)\end{array}$ & $\begin{array}{l}-\mathbf{- 0 . 0 9 8 1 * *} \\
(0.047)\end{array}$ & & & $\begin{array}{l}\mathbf{- 0 . 1 1 2 *} \\
(0.059)\end{array}$ & $\begin{array}{l}-\mathbf{- 0 . 1 5 7 ^ { * * }} \\
(0.072)\end{array}$ \\
\hline Supervisors Have Decision Rights & & & $\begin{array}{l}0.0399^{*} \\
(0.021)\end{array}$ & $\begin{array}{l}0.0356^{*} \\
(0.019)\end{array}$ & $\begin{array}{l}0.0656^{* *} \\
(0.030)\end{array}$ & $\begin{array}{l}0.0683^{* *} \\
(0.031)\end{array}$ \\
\hline Personality Test x Supervisors Have Decision Rights & & & $\begin{array}{l}-\mathbf{0 . 0 6 8 1} * * \\
(0.034)\end{array}$ & $\begin{array}{l}-\mathbf{0 . 0 8 8 1 * *} \\
(0.038)\end{array}$ & $\begin{array}{l}-\mathbf{0 . 1 2 9} * * \\
(0.063)\end{array}$ & $\begin{array}{l}\mathbf{- 0 . 1 6 4 * *} \\
(0.079)\end{array}$ \\
\hline Supervisors Have Decision Rights x Managers Variable Pay & & & & & $\begin{array}{l}-\mathbf{0 . 0 7 3 7} \text { *** } \\
(0.028)\end{array}$ & $\begin{array}{l}-0.0856 * * * \\
(0.032)\end{array}$ \\
\hline Personality Test x Supervisors Decision Rights x Man. Var. Pay & & & & & $\begin{array}{l}0.149^{* *} \\
(0.066)\end{array}$ & $\begin{array}{l}0.172^{* *} \\
(0.085)\end{array}$ \\
\hline Controls for firm size and industry & Yes & Yes & Yes & Yes & Yes & Yes \\
\hline Use Competency Test at Hiring & $\begin{array}{l}0.0303^{*} \\
(0.018)\end{array}$ & $\begin{array}{l}0.0286 \\
(0.018)\end{array}$ & $\begin{array}{l}0.0281 \\
(0.018)\end{array}$ & $\begin{array}{l}0.0301 \\
(0.019)\end{array}$ & $\begin{array}{l}0.0249 \\
(0.018)\end{array}$ & $\begin{array}{l}0.0287 \\
(0.018)\end{array}$ \\
\hline Union and Competition Dummies & No & Yes & No & Yes & No & Yes \\
\hline Constant & $\begin{array}{l}0.0642 \\
(0.040)\end{array}$ & $\begin{array}{l}0.172^{* * *} \\
(0.061)\end{array}$ & $\begin{array}{l}0.0588 \\
(0.042)\end{array}$ & $\begin{array}{l}0.174^{* * *} \\
(0.060)\end{array}$ & $\begin{array}{l}0.0469 \\
(0.044)\end{array}$ & $\begin{array}{l}0.157^{* *} \\
(0.061)\end{array}$ \\
\hline Observations & 2181 & 1588 & 2181 & 1588 & 2181 & 1588 \\
\hline R-squared & 0.85 & 0.86 & 0.85 & 0.86 & 0.86 & 0.86 \\
\hline $\begin{array}{l}\text { OLS - Standard errors in parentheses } \\
* * * p<0.01, * * p<0.05, * p<0.1 \\
\text { Omitted Market Competition: Very High } \\
\text { Omitted Number Competitors: None } \\
\text { Decision Rights = Supervisors Recruit Workers or Set Worker Pay } \\
\text { Variable Pay = ESOPs, Profit-based Payments/Bonuses or Indiv/Te }\end{array}$ & 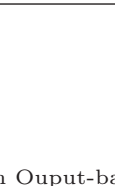 & 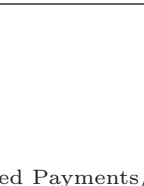 & 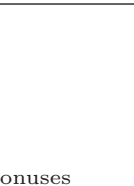 & & & \\
\hline
\end{tabular}

Table 2: WERS - Use of Variable Pay for Non-Managers

Confirming Hypotheses 2 and 4 we find that both interactions Personality Test $\times$ Managers Have Variable Pay and Personality Test $\times$ Supervisors Have Decision Rights are negative and significant on the $5 \%$ level in the relevant specifications 2 and $4 .{ }^{16}$ Thus firms who use personality tests and have variable pay for managers are approximately $10 \%$ less likely to use variable pay for non-managers than one would expect given the main effects of those variables. Similarly, firms who use personality tests and give supervisor decision rights over pay are approximately $10 \%$ less likely to use variable pay for non-managers.

\footnotetext{
${ }^{16}$ For specifications 3 and 4, we define a supervisor as having decision rights if the firm reports that supervisors recruit workers for hiring or set workers' pay. The results are robust to an alternate specification where we say a supervisor has decision rights if he does any of the following: recruit workers for hiring, sets worker pay, determines the pay scheme, or evaluates workers.
} 
Specification 5 and 6 in Table 2 have interactions for Personality Tests, Managers Have Variable Pay and Supervisors Have Decision Rights in combination. The two-way interactions with Personality Tests are both negative, and the sum of all the two-way plus the three way interactions is $-0.234(p<0.003)$. Moreover, if managers do not have variable pay, the joint effect of adding Personality Tests and Supervisors Have Decision Rights is approximately zero and non-significant. However, if Managers Have Variable Pay is true, the overall effect of adding Personality Tests and Supervisors Have Decision Rights is -0.05 $(p<0.001)$. So while the technological main effect of Managers Have Variable Pay is too large to be completely overturned, we can show that the total effect of the other two variables is net negative, and the net negative effect is only present when managers have variable pay (as one would expect from our model). That is, conditional on giving variable pay to managers, firms with both personality tests at hiring and decision rights for supervisors are $5 \%$ less likely overall to give non-managers variable pay than firms that have neither.

To confirm Hypothesis 3 we run an Ordered Probit Estimation. The dependent variable here is "Organizational Scope of Profit-Based Pay", a categorical variable defined as $1=B y$ Workplace, 2 = By Division/Subsidiary, and $3=$ For the Whole Company and capturing on what organizational unit the profit related pay components are calculated. We control for the use of competency tests, standard firm size, industry, union, and competition dummies. Key to our specification is the interaction Use of Personality Test $\times$ Managers have Variable Pay.

\begin{tabular}{|c|c|c|c|}
\hline \multicolumn{4}{|c|}{ Organizational Scope of Profit-Based Pay } \\
\hline COEFFICIENT & (1) & (2) & (3) \\
\hline Managers Have Variable Pay & $\begin{array}{l}0.764^{*} \\
(0.41)\end{array}$ & $\begin{array}{l}0.220 \\
(0.44)\end{array}$ & $\begin{array}{l}0.220 \\
(0.44)\end{array}$ \\
\hline Use Personality Test at Hiring & $\begin{array}{l}1.140^{*} \\
(0.66)\end{array}$ & $\begin{array}{l}2.129^{* *} \\
(0.85)\end{array}$ & $\begin{array}{l}2.129 * * \\
(0.85)\end{array}$ \\
\hline Pers. Test x Man. Var. Pay & $\begin{array}{l}-0.919 \\
(0.70)\end{array}$ & $\begin{array}{l}-1.977^{* *} \\
(0.90)\end{array}$ & $\begin{array}{l}-1.977^{* *} \\
(0.90)\end{array}$ \\
\hline Use Competency Test at Hiring & $\begin{array}{l}0.253 \\
(0.20)\end{array}$ & $\begin{array}{l}0.151 \\
(0.20)\end{array}$ & $\begin{array}{l}0.151 \\
(0.20)\end{array}$ \\
\hline SIC - Education & $\begin{array}{l}9.101^{* * *} \\
(0.39)\end{array}$ & $\begin{array}{l}9.998^{* * *} \\
(0.54)\end{array}$ & \\
\hline Union and Competition Dummies & No & Yes & Yes \\
\hline \multicolumn{4}{|l|}{ Constants } \\
\hline By Division/Subsidiary & $\begin{array}{l}1.861^{* * *} \\
(0.68)\end{array}$ & $\begin{array}{l}1.222 \\
(0.92)\end{array}$ & $\begin{array}{l}1.222 \\
(0.92)\end{array}$ \\
\hline For the Whole Company & $\begin{array}{l}2.188^{* * *} \\
(0.67)\end{array}$ & $\begin{array}{l}1.602^{*} \\
(0.92)\end{array}$ & $\begin{array}{l}1.602^{*} \\
(0.92)\end{array}$ \\
\hline Observations & 673 & 550 & 546 \\
\hline \multicolumn{4}{|c|}{ Note: Foreign Owned is dropped due to no nonzero observations (given other missing values) } \\
\hline \multicolumn{4}{|c|}{$\begin{array}{l}\text { Note: Specification (3) excludes four observations reported as fully } \\
\text { determined in specification }(2) \text { to verify the validity of the standard errors } \\
\text { "For what part of your organisation is the amount of profit-related pay calculated?" } \\
1=\text { By Workplace; } 2=\text { By Division/Subsidiary; } 3=\text { For the Whole Company }\end{array}$} \\
\hline $\begin{array}{l}\text { Ordered Probit - Standard errors } \\
* * * p<0.01, \quad * * p<0.05, \quad * p\end{array}$ & $\begin{array}{l}\text { parenthese } \\
0.1\end{array}$ & & \\
\hline
\end{tabular}

Table 3: WERS - Organizational Scope 
Inspecting Table 3 confirms our Hypothesis 3. The scope of managerial incentives is the dependent variable and we find that the interaction Use of Personality Test $\times$ Managers have Variable Pay is negative and significant on the 5\% level in the relevant specification with controls, i.e. a firm is less likely to have broadly defined performance pay if it screens for reciprocal types and managers' pay depends on their workers' output.

\subsection{Discussion}

Since we only have cross-sectional data and data limitations restrict us to very conservative tests of the model, we are obviously not claiming to establish causality. However, it is noteworthy that we find our quite subtle predictions on the interaction effects consistently in the data. Furthermore, to our knowledge, these patterns of the data were not previously known or studied nor was our theoretical model tailored to generate them. To the contrary, only our theoretical analysis led us to check for these interaction effects.

As noted above, an alternative hypothesis to explain our results could be that the use of personality tests and managerial incentive pay are signs of firms with more sophisticated personnel policies. Indeed, the use of these policies is strongly correlated with firm size. However, if sophistication was the sole determinant, we would expect, if anything, that more sophisticated firms are more (rather than less) likely to use incentives also for non-managers. Managerial incentives would already necessitate the collection of performance measures, lowering the marginal cost of extending these monetary incentives to non-managers. The WERS provides us with two variables which we can arguably use as proxies for sophisticated personnel policies: We know the number of staff dealing specifically with personnel issues in the workplace and we know whether there is an equal opportunity or diversity management policy in place in the workplace. Including these proxies (separately or jointly) in our regressions neither qualitatively nor quantitatively change our results. If anything the size of the relevant interaction effects increases. Hence our regression results are qualitatively and quantitatively robust to including these two (admittedly crude) measures of personnel policy sophistication.

Misaligned performance measures, a prominent explanation for the lack of explicit incentives, would not imply a variation with respect to finding workers of the appropriate preference type. Therefore, while we might have expected a main effect, it cannot explain a significant interaction effect between organizational structure and the use of personality tests. Similarly, while intrinsic motivation could suggest an overall low level of incentives, 
again there is no reason to expect that organizational features such as the presence of managerial incentives, or managerial discretion over pay, would enhance intrinsic motivation and thus can explain the empirical result.

If firms use monitoring instead of explicit incentives for workers, then we would also expect to get our result that less variable pay for non-managers correlates with more variable pay and more decision rights for managers, however there is no reason to expect that personality tests should have an effect in a monitoring story. If firms use career incentives instead of explicit incentives for workers, we might expect a main effect of personality tests, as the use of career concerns implies that workers stay with the firm for longer, hence fit becomes more important and personality tests are used more often. This main effect of personality tests, however, is always (a) non-significant, and (b) directionally positive, i.e. more use of personality tests correlates with more use of non-manager performance pay. Moreover, again there is no reason to expect any systematic interaction effects. Using career concerns as an incentive device should work equally well whether a senior manager or the supervisor is setting pay, or whether the supervisor has performance pay or not.

Our interpretation stresses the importance of a close relation between workers and their supervisors. Collusion between those comes to mind as a potential danger to the firm. Though this is certainly an important and valid concern, empirically a collusion story would suggest that giving strong incentives not only to managers but also workers is important and would hence predict a positive interaction effect. Finally our assumption that the use of personality tests upon hiring leads to a more reciprocal workforce, though implied by Autor and Scarborough (forthcoming), can be scrutinized. How can we rule out that firms in fact do not use personality tests to specifically select selfish workers? Note, if (some) firms screen in a way that leads to more selfish workers being hired, then we should not expect them to use reciprocal incentives, as they would be doomed to fail. Hence our estimates underestimate the true effect within firms that select reciprocal workers and use reciprocal incentives.

Unconditional forms of social preferences based on distributions, such as pure altruism or inequity aversion, may suggest that the allocation of rents to a manager via managerial incentives could affect the effort decision of a non-managerial worker. However, these models all depend purely on the payoff outcomes, not on who takes any particular action nor on their intentions. Therefore these models cannot explain the interaction effect with managerial decision making. Thus, though we do not want to over-interpret our findings, we find the results to be suggestive and hard to explain with alternative stories, hence lending support 
to our interpretation.

\section{Conclusion}

The importance of fairness and social preferences especially for the work relation has long been documented. We focus on reciprocity, a widely studied form of social preferences, particularly in the experimental literature. Despite its prominence in experimental economics, there is so far no theoretical analysis of how exactly reciprocity affects the employment relation in the presence of moral hazard. We solve for the optimal contract in the basic principalagent problem and show that reciprocal motivations and explicit performance-based pay are substitutes, and that using reciprocal incentives decreases agency costs. Furthermore, we show that the optimal contract entails an optimal mix of both incentive forms: using explicit incentives less when the agent is more reciprocal, and using them more when output is a more informative signal of effort. Our results highlight the importance of the magnitude of the benefit to the principal from high effort in enhancing the role for reciprocal incentives.

This last finding allows us to extend our model to capture features of organizational structure. We predict a collocation of incentive pay and decision rights in a firm's hierarchy in firms that use personality tests in their hiring procedure. Furthermore, in those firms incentive pay for non-managers should be less prevalent, i.e. they rely more on reciprocal incentives, and the scope of performance pay for managers should be more narrowly defined. In the UK WERS workplace survey we find these predictions of our extended model confirmed.

Our study indicates that employing agents' reciprocity as a part of a firms personnel policy is a potentially promising alternative. However, it is important that various complementary parts of a firm's compensation and HR policy are coordinated to maximize the effect of reciprocity. The size of gifts and the receiver of the reciprocal act have to be identified, and naturally a firm's hiring policy should also be adjusted to the intended use of compensation practices - if a firm plans to make use of reciprocity, the hired workforce better be reciprocal.

Obviously our study is but a step in the direction of more fully exploring this field. There are various directions where this model could be developed to in order to allow further theoretical as well as empirical analysis. Multitasking is a natural first step. Following Holmström and Milgrom (1991) a certain degree of intrinsic motivation is an important ingredient to achieve (close to) efficient allocation of effort across different dimensions. In- 
troducing reciprocal motivations into their model could serve as a way to provide a specific micro-foundation for this intrinsic motivation. Hence studying multi-tasking together with reciprocity should allow us to derive further detailed and testable predictions about contracts and organizational structure.

Another possible direction would be to consider several firms employing a mixture of selfish and reciprocal workers. Reciprocal workers are "valuable" to the firm, in the sense that agency costs are lower for highly reciprocal workers. Hence it is possible that competition for reciprocal workers may cause segmentation in the market, where a niche of "high culture" firms extensively uses personality tests to screen their new hires, employs reciprocal workers, and provides generous but flat compensation packages, while other firms employ selfish workers with strong explicit incentives. ${ }^{17}$

Lastly, further empirical work can explore the optimal magnitude of the gift and the proper mix between reciprocal and explicit motivation to maximize the profitability of gift exchange. Our theoretical model suggests that a job where explicit incentives work poorly due to a noisy production function, and where output is highly valuable to the principal is the environment where reciprocal incentives should be striving.

\section{$5 \quad$ Appendix}

\subsection{Proof of $\eta^{*}$ (For both the two-action and multiple-action case)}

By construction the Principal's problem is a convex minimization with linear constraints. Therefore, for a given set of parameters, the optimal solution is unique. Moreover, by Proposition 1 (for the two-action case) or Proposition 12 (for the multiple-action case) we know that the value function for the principal's problem is non-increasing in $\eta$. We proceed by showing that the value function $V(\eta)$ is absolutely continuous in $\eta$. Since we know from the sketch of the proof in the main text that there is an $\eta$ large enough that the value function is strictly smaller than for the standard $\eta=0$ case, given absolute continuity, there must be some $\eta^{*}$ such that for $\eta \leq \eta^{*} V(\eta)=V(0)$ (and therefore the standard contract is optimal), and for $\eta>\eta^{*}$ it holds that $V(\eta)<V(0)$ (and therefore a reciprocity contract is optimal). Moreover, since the solution for any $\eta$ is unique, $\eta^{*}$ is the point such that the optimal contract derived by ignoring the [IR] coincides with the standard contract. Additionally, when $\eta>\eta^{*}$

\footnotetext{
${ }^{17}$ See Kosfeld and von Siemens (2007) for a first step in this direction.
} 
we know that the optimal contract provides a strictly positive rent. Hence in this region, we know that if we solve for the optimal contract by ignoring the [IR], we know that the solution will in fact meet the [IR].

To prove the lemma, we prove continuity for the multiple action case.

\section{Proof of continuity}

Recall that in the multi-action case we have: $N$ is the number of states, $M$ is the number of actions, $a \in A$ is the set of actions and $u \in(u(\underline{w}), \infty)$ is the set of utilities.

The Principal's Implementation Problem for $\hat{a}$ is the program $P$ :

$$
\max _{u}-\sum_{i} \pi_{i}(\hat{a}) h\left(u_{i}\right) \quad \text { s.t. } \quad[I R] \quad \sum_{i} \pi_{i}(\hat{a}) u_{i}-c(\hat{a})-\bar{u} \geq 0
$$

and $\quad[I C] \sum_{i} \pi_{i}(\hat{a}) u_{i}-c(\hat{a})+\eta\left(\sum_{i} \pi_{i}(\hat{a}) u_{i}-c(\hat{a})-\bar{u}\right)\left(\sum_{i} \pi_{i}(\hat{a}) q_{i}\right) \geq$

$$
\sum_{i} \pi_{i}(a) u_{i}-c(a)+\eta\left(\sum_{i} \pi_{i}(\hat{a}) u_{i}-c(\hat{a})-\bar{u}\right)\left(\sum_{i} \pi_{i}(a) q_{i}\right) \quad \forall a \in A
$$

Let $V(\eta ; \hat{a})=-\max _{u}\left(-\sum_{i} \pi_{i}(\hat{a}) h\left(u_{i}^{*}\right)\right)$ denote the value function, where $u^{*}$ is a solution to $P$.

Proposition $9 V(\eta)$ is absolutely continuous in $\eta$.

Proof. Consider the constrained program $P^{\prime}$ where $u \in U^{\prime}=(u(w), \bar{U}]^{N}$ where $\bar{U}$ is a finite number such that

$$
V(0 ; \hat{a})>-\underline{\pi} h(\bar{U})-(1-\underline{\pi}) \underline{w} \quad \forall \quad a \in A
$$

where $\underline{\pi}=\min _{a, i} \pi_{i}(a)$ i.e. the smallest state probability. Hence $\bar{U}$ is a payment sufficiently large so that the cheapest possible contract involving a payment of $\bar{U}$ is strictly dominated by the standard contract. Hence any contract involving any payment larger than $\bar{U}$ will also be strictly dominated

Therefore the program $P^{\prime}$ is equivalent to $P$, since their solution sets will be identical (any contract feasible in $P$ but not in $P^{\prime}$ is strictly dominated by a contract that is feasible in both). Hence $V^{\prime}(\eta)=V(\eta)$.

Now consider the constrained program $P^{\prime \prime}$ where $u \in U^{\prime \prime}=[\underline{u}, \bar{U}]^{N}$ and where $(1-\underline{\pi}) \bar{U}+$ $\underline{\pi u}=u_{0}+\hat{c}$. Any contract that involves a utility payment smaller than $\underline{\mathrm{u}}$ violates the [IR], 
and thus is infeasible. Therefore the set of feasible contracts is identical between $P^{\prime}$ and $P^{\prime \prime}$, so the programs are equivalent. Hence $V^{\prime \prime}(\eta)=V^{\prime}(\eta)=V(\eta)$.

Since $U^{\prime \prime}$ is a compact, convex set; the continuity, concavity and differential conditions on the objective function and the constraints are met, and a feasible point exists where all the constraints are slack, the conditions of Milgrom and Segal (2002, Corollary 5) are met, proving absolute continuity.

Corollary 5 from Milgrom and Segal (2002, pp. 597f):

Suppose that $X$ is a convex compact set in a normed linear space, $f$ and $g$ are continuous and concave in $x, f_{t}(x, t)$ and $g_{t}(x, t)$ are continuous in $(x, t)$, and there exists $\hat{x} \in X$ such that $g(\hat{x}, t)>>0$ for all $t \in[0,1]$. Then:

(i) $V$ is absolutely continuous, and for any selection $\left(x^{*}(t), y^{*}(t)\right) \in X^{*}(t) \times Y^{*}(t)$,

$$
V(t)=V(0)+\int_{0}^{t} L_{t}\left(x^{*}(s), y^{*}(s), s\right) d s
$$

(ii) $V$ is directionally differentiable, and its directional derivatives equal:

$$
\begin{aligned}
& V^{\prime}(t+)=\max _{x \in X^{*}(t)} \min _{y \in Y^{*}(t)} L_{t}(x, y, t)=\min _{y \in Y^{*}(t)} \max _{x \in X^{*}(t)} L_{t}(x, y, t) \text { for } \quad t<1 \\
& V^{\prime}(t-)=\min _{y \in Y^{*}(t)} \max _{x \in X^{*}(t)} L_{t}(x, y, t)=\max _{x \in X^{*}(t)} \min _{y \in Y^{*}(t)} L_{t}(x, y, t) \text { for } \quad t>0
\end{aligned}
$$

Hence $V(\eta)$ is absolutely continuous in $\eta$, and thus the lemma follows.

\subsection{The Optimal Contract for CRRA Utility}

Proposition 10 For CRRA utility, the optimal contract is:

$u_{i}=K\left(\Phi_{i}(\eta)\right)^{\frac{1-\gamma}{\gamma}} \quad$ where $\quad K=\frac{\Delta c+(\bar{u}+c(\hat{a})) \eta \Delta E R}{\sum \pi_{i}(\hat{a})\left(\Phi_{i}(\eta)\right)^{1 / \gamma}} \quad$ and $\quad \Phi_{i}(\eta)=1-\frac{\pi_{i}\left(a_{1}\right)}{\pi_{i}(\hat{a})}+\eta \Delta E R$

and $\eta^{*}$ is defined implicitly by

$$
(\bar{u}+c(\hat{a}))\left[\sum \pi_{i}\left(a_{1}\right)\left(\Phi_{i}\left(\eta^{*}\right)\right)^{\frac{1-\gamma}{\gamma}}\right]=\left(\bar{u}+c\left(a_{1}\right)\right)\left[\sum \pi_{i}(\hat{a})\left(\Phi_{i}\left(\eta^{*}\right)\right)^{\frac{1-\gamma}{\gamma}}\right]
$$

Proof. To ease exposition define $\Phi_{i}=\Phi_{i}(\eta)$. We take the FOC assuming that the [IR] is slack. $h^{\prime}\left(u_{i}\right)=\left((1-\gamma) u_{i}\right)^{\frac{\gamma}{1-\gamma}}=\lambda_{I C}\left(1-\frac{\pi_{i}\left(a_{1}\right)}{\pi_{i}(\hat{a})}+\eta \Delta E R\right)=\lambda_{I C} \Phi_{i}$. With $K=\frac{\lambda_{I C}^{\frac{1-\gamma}{\gamma}}}{1-\gamma}$ we can transform this to $u_{i}=K\left(\Phi_{i}\right)^{\frac{1-\gamma}{\gamma}}$. 
We can solve for $K$ explicitly using the [IC] (which holds with equality)

$$
\begin{aligned}
\sum\left(\pi_{i}(\hat{a})-\pi_{i}\left(a_{1}\right)\right) u_{i}+\eta\left(\sum \pi_{i}(\hat{a}) u_{i}\right) \Delta E R & =(\bar{u}+c(\hat{a})) \eta \Delta E R+\Delta c \\
K \sum \pi_{i}(\hat{a})\left(1-\frac{\pi_{i}\left(a_{1}\right)}{\pi_{i}(\hat{a})}+\eta \Delta E R\right)\left(\Phi_{i}\right)^{\frac{1-\gamma}{\gamma}} & =(\bar{u}+c(\hat{a})) \eta \Delta E R+\Delta c \\
K \sum \pi_{i}(\hat{a})\left(\Phi_{i}\right)^{\frac{1}{\gamma}} & =(\bar{u}+c(\hat{a})) \eta \Delta E R+\Delta c \\
K & =\frac{(\bar{u}+c(\hat{a})) \eta \Delta E R+\Delta c}{\sum \pi_{i}(\hat{a})\left(\Phi_{i}\right)^{\frac{1}{\gamma}}}
\end{aligned}
$$

We can get a formula for $\eta^{*}$ by plugging the optimal contract into a binding [IR] (since at $\eta^{*}$ the optimal reciprocity contract must coincide with the standard contract, where the [IR] binds).

$$
\begin{aligned}
& \bar{u}+c(\hat{a})=K \sum \pi_{i}(\hat{a})\left(\Phi_{i}\right)^{\frac{1-\gamma}{\gamma}} \\
& \bar{u}+c(\hat{a})=\left(\frac{(\bar{u}+c(\hat{a})) \eta \Delta E R+\Delta c}{\sum \pi_{i}(\hat{a})\left(\Phi_{i}\right)^{\frac{1}{\gamma}}}\right) \sum \pi_{i}(\hat{a})\left(\Phi_{i}\right)^{\frac{1-\gamma}{\gamma}} \\
& (\bar{u}+c(\hat{a}))\left(\sum \pi_{i}(\hat{a}) \Phi_{i}^{\frac{1}{\gamma}}\right)=((\bar{u}+c(\hat{a})) \eta \Delta E R+\Delta c) \sum \pi_{i}(\hat{a})\left(\Phi_{i}\right)^{\frac{1-\gamma}{\gamma}} \\
& (\bar{u}+c(\hat{a}))\left(\sum \pi_{i}(\hat{a})\left(\Phi_{i}^{\frac{1}{\gamma}}-\eta \Delta E R \Phi_{i}^{\frac{1-\gamma}{\gamma}}\right)\right)=\Delta c \sum \pi_{i}(\hat{a}) \Phi_{i}^{\frac{1-\gamma}{\gamma}} \\
& (\bar{u}+c(\hat{a}))\left(\sum \pi_{i}(\hat{a})\left(\Phi_{i}-\eta \Delta E R\right) \Phi_{i}^{\frac{1-\gamma}{\gamma}}\right)=\Delta c \sum \pi_{i}(\hat{a}) \Phi_{i}^{\frac{1-\gamma}{\gamma}} \\
& (\bar{u}+c(\hat{a}))\left(\sum \pi_{i}(\hat{a})\left(1-\frac{\pi_{i}\left(a_{1}\right)}{\pi_{i}(\hat{a})}\right) \Phi_{i}^{\frac{1-\gamma}{\gamma}}\right)=\Delta c \sum \pi_{i}(\hat{a}) \Phi_{i}^{\frac{1-\gamma}{\gamma}} \\
& (\bar{u}+c(\hat{a}))\left(\sum\left(\pi_{i}(\hat{a})-\pi_{i}\left(a_{1}\right)\right) \Phi_{i}^{\frac{1-\gamma}{\gamma}}\right)=\Delta c \sum \pi_{i}(\hat{a}) \Phi_{i}^{\frac{1-\gamma}{\gamma}} \\
& (\bar{u}+c(\hat{a})-\Delta c)\left(\sum \pi_{i}(\hat{a}) \Phi_{i}^{\frac{1-\gamma}{\gamma}}\right)=(\bar{u}+c(\hat{a}))\left(\sum \pi_{i}\left(a_{1}\right) \Phi_{i}^{\frac{1-\gamma}{\gamma}}\right) \\
& \left(\bar{u}+c\left(a_{1}\right)\right)\left(\sum \pi_{i}(\hat{a}) \Phi_{i}^{\frac{1-\gamma}{\gamma}}\right)=(\bar{u}+c(\hat{a}))\left(\sum \pi_{i}\left(a_{1}\right) \Phi_{i}^{\frac{1-\gamma}{\gamma}}\right)
\end{aligned}
$$

Thus $\eta^{*}$ is defined implicitly s.t. the above equation holds.

\subsection{The Optimal Contract for CARA Utility}

Proposition 11 For CARA utility, the optimal contract is:

$u_{i}=K\left(\Phi_{i}(\eta)\right)^{-1} \quad$ where $\quad K=\Delta c+(\bar{u}+c(\hat{a})) \eta \Delta E R \quad$ and $\quad \Phi_{i}(\eta)=1-\frac{\pi_{i}\left(a_{1}\right)}{\pi_{i}(\hat{a})}+\eta \Delta E R$ and $\eta^{*}$ is defined implicitly by

$$
(\bar{u}+c(\hat{a}))\left[\sum \pi_{i}\left(a_{1}\right)\left(\Phi_{i}\left(\eta^{*}\right)\right)^{-1}\right]=\left(\bar{u}+c\left(a_{1}\right)\right)\left[\sum \pi_{i}(\hat{a})\left(\Phi_{i}\left(\eta^{*}\right)\right)^{-1}\right]
$$


Proof. Again for convenience define $\Phi_{i}=\Phi_{i}(\eta)$. We solve using the FOC's assuming the [IR] is slack. $h^{\prime}\left(u_{i}\right)=\frac{1}{-\alpha u_{i}}=\lambda_{I C}\left(1-\frac{\pi_{i}\left(a_{1}\right)}{\pi_{i}(\hat{a})}+\eta \Delta E R\right)=\lambda_{I C} \Phi_{i}$. With $K=\frac{1}{-\alpha \lambda_{I C}}$ we can transform this to $u_{i}=K\left(\Phi_{i}\right)^{-1}$.

We solve for $K$ explicitly using the [IC] (which holds with equality)

$$
\begin{aligned}
\sum\left(\pi_{i}(\hat{a})-\pi_{i}\left(a_{1}\right)\right) u_{i}+\eta\left(\sum \pi_{i}(\hat{a}) u_{i}\right) \Delta E R & =(\bar{u}+c(\hat{a})) \eta \Delta E R+\Delta c \\
K \sum \pi_{i}(\hat{a})\left(1-\frac{\pi_{i}\left(a_{1}\right)}{\pi_{i}(\hat{a})}+\eta \Delta E R\right)\left(\Phi_{i}\right)^{-1} & =(\bar{u}+c(\hat{a})) \eta \Delta E R+\Delta c \\
K \sum \pi_{i}(\hat{a})=K & =(\bar{u}+c(\hat{a})) \eta \Delta E R+\Delta c
\end{aligned}
$$

We derive a formula for $\eta^{*}$ by plugging the optimal contract into a binding [IR].

$$
\begin{array}{rlrl}
K \sum \pi_{i}(\hat{a}) \Phi_{i}^{-1} & = & \bar{u}+c(\hat{a}) & \\
(\Delta c+(\bar{u}+c(\hat{a})) \eta \Delta E R) \sum \pi_{i}(\hat{a}) \Phi_{i}^{-1} & = & \bar{u}+c(\hat{a}) \\
(\Delta c+(\bar{u}+c(\hat{a})) \eta \Delta E R) \sum \pi_{i}(\hat{a}) \Phi_{i}^{-1} & = & & (\bar{u}+c(\hat{a})) \sum \pi_{i}(\hat{a}) \Phi_{i}\left(\Phi_{i}\right)^{-1} \\
\Delta c \sum \pi_{i}(\hat{a}) \Phi_{i}^{-1} & = & (\bar{u}+c(\hat{a})) \sum \pi_{i}(\hat{a})\left(\Phi_{i}-\eta \Delta E R\right)\left(\Phi_{i}\right)^{-1} \\
\Delta c \sum \pi_{i}(\hat{a}) \Phi_{i}^{-1} & = & (\bar{u}+c(\hat{a})) \sum \pi_{i}(\hat{a})\left(1-\frac{\pi_{i}\left(a_{1}\right)}{\pi_{i}(\hat{a})}\right)\left(\Phi_{i}\right)^{-1} \\
\Delta c \sum \pi_{i}(\hat{a}) \Phi_{i}^{-1} & = & (\bar{u}+c(\hat{a})) \sum\left(\pi_{i}(\hat{a})-\pi_{i}\left(a_{1}\right)\right)\left(\Phi_{i}\right)^{-1} \\
\Delta c \sum \pi_{i}(\hat{a}) \Phi_{i}^{-1} & = & (\bar{u}+c(\hat{a})) \sum\left(\pi_{i}(\hat{a})-\pi_{i}\left(a_{1}\right)\right)\left(\Phi_{i}\right)^{-1} \\
(\bar{u}+c(\hat{a})) \sum \pi_{i}\left(a_{1}\right)\left(\Phi_{i}\right)^{-1} & = & (\bar{u}+c(\hat{a})-\Delta c) \sum \pi_{i}(\hat{a})\left(\Phi_{i}\right)^{-1} \\
(\bar{u}+c(\hat{a})) \sum \pi_{i}\left(a_{1}\right)\left(\Phi_{i}\right)^{-1} & = & \left(\bar{u}+c\left(a_{1}\right)\right) \sum \pi_{i}(\hat{a})\left(\Phi_{i}\right)^{-1}
\end{array}
$$

Thus $\eta^{*}$ is defined implicitly s.t. the above equation holds.

\subsection{Proof of Lemma 4}

Lemma 4 If $G$ differs from $F$ by only a single $M P S, w^{*}(G), x^{*}(F)$ are the optimal contracts given the distribution of likelihood ratios, and $\eta \geq \max \left[\eta^{*}(F), \eta^{*}(G)\right]$ then $w^{*}(G) \succ_{m u} x^{*}(F)$.

Proof. Since the number of states (and thus the number of distinct likelihood ratios) is fixed between $F$ and $G$, then for $G$ to differ from $F$ by a single MPS it means there is a state $\tilde{j}$ whose likelihood ratio decreased from $1-\frac{\pi_{\tilde{j}}^{F}}{\hat{\pi}_{\tilde{j}}^{F}}$ to $1-\frac{\pi_{\tilde{j}}^{F}}{\hat{\pi}_{\tilde{j}}^{F}}-\underline{\delta}$, and a state $\tilde{i}>\tilde{j}$ whose likelihood ratio increased from $1-\frac{\pi_{i}^{F}}{\hat{\pi}_{\tilde{i}}^{F}}$ to $1-\frac{\pi_{\hat{i}}^{F}}{\hat{\pi}_{\tilde{i}}^{F}}+\underline{\delta}$. All other states have the same likelihood 
ratios. Then we have for any $j \leq j^{*}$

$$
\begin{aligned}
& \frac{u^{\prime}\left(w_{j}^{*}(G)\right)}{u \prime\left(w_{\hat{i}}^{*}(G)\right)}=\frac{1-\frac{\pi_{i}^{G}}{(\hat{\pi})_{\hat{i}}^{G}}+\eta \Delta E R(\hat{a})}{1-\frac{\pi_{j}^{G}}{(\hat{\pi})_{j}^{G}}+\eta \Delta E R(\hat{a})}=\frac{1-\frac{\pi_{\tilde{i}}^{F}}{(\hat{\pi})_{\hat{i}}^{F}}+\bar{\delta}+\eta \Delta E R(\hat{a})}{1-\frac{\pi_{j}^{F}}{(\hat{\pi})_{j}^{F}}+\eta \Delta E R(\hat{a})} \\
&> \frac{1-\frac{\pi_{i}^{F}}{(\hat{\pi})_{\tilde{i}}^{F}}+\eta \Delta E R(\hat{a})}{1-\frac{\pi_{j}^{F}}{(\hat{\pi})_{j}^{F}}+\eta \Delta E R(\hat{a})}=\frac{u^{\prime}\left(x_{j}^{*}(F)\right)}{u \prime\left(x_{i^{*}}^{*}(F)\right)}
\end{aligned}
$$

and for any $i \geq \tilde{i}$

$$
\begin{aligned}
\frac{u^{\prime}\left(w_{\tilde{j}}^{*}(G)\right)}{u^{\prime}\left(w_{i}^{*}(G)\right)}=\frac{1-\frac{\pi_{i}^{G}}{(\hat{\pi})_{i}^{G}}+\eta \Delta E R(\hat{a})}{1-\frac{\pi_{\tilde{j}}^{G}}{(\hat{\pi})_{\tilde{j}}^{G}}+\eta \Delta E R(\hat{a})}=\frac{1-\frac{\pi_{i}^{G}}{(\hat{\pi})_{i}^{G}}+\eta \Delta E R(\hat{a})}{1-\frac{\pi_{\hat{j}}^{G}}{(\hat{\pi})_{\tilde{j}}^{G}}-\underline{\delta}+\eta \Delta E R(\hat{a})} \\
>\frac{1-\frac{\pi_{i}^{F}}{(\hat{\pi})_{i}^{F}}+\eta \Delta E R(\hat{a})}{1-\frac{\pi_{\tilde{j}}^{F}}{(\hat{\pi})_{\tilde{j}}^{F}}+\eta \Delta E R(\hat{a})}=\frac{u^{\prime}\left(x_{\hat{j}}^{*}(F)\right)}{u^{\prime}\left(x_{i}^{*}(F)\right)}
\end{aligned}
$$

With all other comparisons equal. Hence $w^{*}(G) \succ_{m u} x^{*}(F)$ for $(\tilde{i}, \tilde{i}, \tilde{j}, \tilde{j})$. Moreover for any state $\tilde{k}$ where $\tilde{j} \leq \tilde{k} \leq \tilde{i}, w^{*}(G) \succ_{m u, \tilde{k}} x^{*}(F)$.

\subsection{Proof of Proposition 5}

Proposition 5 If $G$ is an MPS of $F, w^{*}(G), x^{*}(F)$ are the optimal contracts given the distribution of likelihood ratios, and $\eta \geq \max \left[\eta^{*}(F), \eta^{*}(G)\right]$ then $w^{*}(G) \succ_{m u} x^{*}(F)$. Additionally, if $G$ is a balanced MPS of $F$, then $w^{*}(G) \succ_{m u, \breve{i}} x^{*}(F)$.

Proof. From Lemma 1 in Rothschild and Stiglitz (1970) (with corrected proof in Leshno, Levy and Spector(1997)), there exists a sequence of distributions $F_{0}, \ldots, F_{L}$ such that $F_{0}=$ $F, F_{L}=G$, and $F_{l}$ differs from $F_{l-1}$ by only an MPS. Each $F_{l}$ induces a reciprocity contract $x^{*}\left(F_{l}\right)$ (i.e. the solution to the principal's problem given $F_{l}$ assuming that $\lambda_{I R}=0$ ). We do not need that for each $F_{l}$ the optimal reciprocity contract is preferred to the optimal standard contract, only that if the optimal reciprocity contract is well defined for both $G$ and $F$, then it will be well defined for all $F_{l}$.

For the reciprocity contract to be well defined, we need $\eta$ large enough that $\frac{1}{u^{\prime}\left(x_{1}^{*}\left(F_{l}\right)\right)}=$ $1-\frac{\pi_{1} F_{l}}{(\hat{\pi})_{1} F_{l}}+\eta \Delta E R(\hat{a}) \geq 0$, which will ensure that all the marginal utilities are positive and so there is a wage payment that satisfies the FOC. 
However, we know $1-\frac{\pi_{1}^{F_{l}}}{(\hat{\pi})_{1}^{F_{l}}} \geq 1-\frac{\pi_{1}^{G}}{(\hat{\pi})_{1}^{G}}$ and so $\frac{1}{u^{\prime}\left(x_{1}^{*}\left(F_{l}\right)\right)} \geq \frac{1}{u^{\prime}\left(x_{1}^{*}(G)\right)}=1-\frac{\pi_{1}^{G}}{(\hat{\pi})_{1}^{G}}+\eta \Delta E R(\hat{a}) \geq 0$. Therefore $x^{*}\left(F_{l}\right)$ is well defined for all $F_{l}$. From our Lemma 4 above we know $x^{*}\left(F_{l}\right) \succ_{m u}$ $x^{*}\left(F_{l-1}\right)$, and with transitivity the result obtains.

Additionally, note that if $G$ is a balanced MPS of $F$ with $\tilde{i}$ the largest state below the balance point, then for each $F_{l}$, the states with increasing and decreasing likelihood ratios will be above and below $\tilde{i}$ (respectively), and therefore $x^{*}\left(F_{l}\right) \succ_{m u, \breve{i}} x^{*}\left(F_{l-1}\right)$ for each $F_{l}$.

\subsection{Multiple Action Case}

\subsubsection{General Results without Additional Distributional Assumptions}

Consider the case where the agent is choosing between a set of actions $a_{1}<a_{2}<\ldots<a_{m}$. We assume that $c(a)$ is increasing and convex in $a$, and that $E R(a)$ is increasing and concave in $a$. We begin by considering which results extend from the two action case without any further assumptions on the distribution of output. As before, we focus on the implementation problem. The principal's problem to implement $a_{k}$ is

$$
\begin{array}{ll}
\min _{w\left(q_{i}\right), \hat{a}} \quad \sum \pi_{i}\left(a_{k}\right) w\left(q_{i}\right) & \\
\text { s.t. } & {[I R] \quad U\left(a_{k}, \hat{a}\right) \geq \bar{u} \quad ; \quad[I C] \quad U\left(a_{k}, \hat{a}\right) \geq U\left(a^{\prime}, \hat{a}\right) \forall a^{\prime} \quad ; \quad[E B] \quad \hat{a}=a_{k} .}
\end{array}
$$

Substituting in $\hat{a}=a_{k}$ to satisfy [EB] and transforming the [IR] and [IC] we get

$$
\begin{array}{ll}
\min _{u_{i}} & \sum \pi_{i}(\hat{a}) h\left(u_{i}\right) \\
\text { s.t. } & \sum \pi_{i}(\hat{a}) u_{i}-c(\hat{a})-\bar{u} \geq 0 \\
\text { s.t. } & \sum\left(\pi_{i}(\hat{a})-\pi_{i}\left(a^{\prime}\right)\right) u_{i}+\eta\left(\sum \pi_{i}(\hat{a}) u_{i}-c(\hat{a})-\bar{u}\right)\left(E R(\hat{a})-E R\left(a^{\prime}\right)\right) \geq c(\hat{a})-c\left(a^{\prime}\right) \forall a^{\prime}
\end{array}
$$

With the FOC's analogous to the two-action case

$$
h^{\prime}\left(u_{i}\right)=\lambda_{I R}+\sum_{k} \lambda_{I C-k}\left[1-\frac{\pi_{i}\left(a_{k}\right)}{\pi_{i}(\hat{a})}+\eta\left(E R(\hat{a})-E R\left(a_{k}\right)\right)\right] .
$$

First, notice that Observations 1 - optimality of the standard contract for $\eta=0$ - and 2 the standard contract is implementable for all $\eta$ - extend directly from the two-action case. For $\eta=0$ the agent is selfish, and in general the standard contract provides zero rent to the agent, so the reciprocal portion of his utility drops out. Therefore the standard contract 
will implement $\hat{a}$ for any $\eta$. However, if $\hat{a}$ is not the highest action, it is not the case that any contract that implements $\hat{a}$ for a given $\eta_{1}$ will still implement $\hat{a}$ for any $\eta_{2}>\eta_{1}$. This is because the reciprocal portion of the agent's utility for an upwards [IC] is negative: working harder would give a larger gift back to the principal. Hence if an upwards [IC] is binding, then increasing $\eta$ would make the agent strictly prefer the higher action. However, we can show that for any increase in $\eta$, a translation of the initial contract where all the utility payments are shifted down by a constant $\delta$ will still implement $\hat{a}$.

Lemma 5 If $u_{i}$ implements $\hat{a}$ given $\eta_{1}$ then for any $\eta_{2}>\eta_{1}, \exists \delta \geq 0$ such that $v_{i}=u_{i}-\delta$ implements $\hat{a}$.

Proof. Let $\delta=\left(1-\frac{\eta_{1}}{\eta_{2}}\right)\left[\sum \pi_{i}(\hat{a}) u_{i}-\bar{u}-c(\hat{a})\right]$. For the $[\mathrm{IR}]$ we have

$$
\begin{aligned}
\sum \pi_{i}(\hat{a}) v_{i}-c(\hat{a})-\bar{u} & =\left[\sum \pi_{i}(\hat{a}) u_{i}-c(\hat{a})-\bar{u}\right]-\delta \\
& =\left[\sum \pi_{i}(\hat{a}) u_{i}-c(\hat{a})-\bar{u}\right]-\left(1-\frac{\eta_{1}}{\eta_{2}}\right)\left[\sum \pi_{i}(\hat{a}) u_{i}-\bar{u}-c(\hat{a})\right] \\
& =\left(\frac{\eta_{1}}{\eta_{2}}\right)\left[\sum \pi_{i}(\hat{a}) u_{i}-\bar{u}-c(\hat{a})\right] \geq 0
\end{aligned}
$$

Hence we can hold constant the value the agent places on the rent by scaling down the rent by the ratio of $\eta_{1}$ to $\eta_{2}$.

And for any $[\mathrm{IC}]$ we have

$$
\begin{aligned}
\sum & \left(\pi_{i}(\hat{a})-\pi_{i}\left(a^{\prime}\right)\right) v_{i}+\eta_{2}\left(\sum \pi_{i}(\hat{a}) v_{i}-c(\hat{a})-\bar{u}\right)\left(\operatorname{ER}(\hat{a})-\operatorname{ER}\left(a^{\prime}\right)\right)-\left(c(\hat{a})-c\left(a^{\prime}\right)\right) \\
= & \sum\left(\pi_{i}(\hat{a})-\pi_{i}\left(a^{\prime}\right)\right) u_{i}+\eta_{2}\left(\frac{\eta_{1}}{\eta_{2}}\right)\left[\sum \pi_{i}(\hat{a}) u_{i}-c(\hat{a})-\bar{u}\right]\left(\operatorname{ER}(\hat{a})-E R\left(a^{\prime}\right)\right]-\left(c(\hat{a})-c\left(a^{\prime}\right)\right) \\
= & \sum\left(\pi_{i}(\hat{a})-\pi_{i}\left(a^{\prime}\right)\right) u_{i}+\eta_{1}\left[\sum \pi_{i}(\hat{a}) u_{i}-c(\hat{a})-\bar{u}\right]\left(E R(\hat{a})-E R\left(a^{\prime}\right)\right]-\left(c(\hat{a})-c\left(a^{\prime}\right)\right) \geq \quad \geq
\end{aligned}
$$

Since $\eta$ times the rent is held constant, as is the spread of wage payments across states, if the first contract meets the $[\mathrm{IC}]$ then the second contract will as well.

Thus a cheaper contract with the same explicit incentives will implement $\hat{a}$. This immediately implies that the cost to the principal of the second-best optimal contract is nonincreasing in $\eta$, as it was in the two-action case.

Proposition $12 V(\eta, \hat{a})$ is non-increasing in $\eta$ for all $\hat{a}$.

Proof. For any $\eta_{2}>\eta_{1}$, apply Lemma 12 to the optimal contract given $\eta_{1}$. Therefore, the optimal contract under $\eta_{2}$ must have at least as small a cost to the principal as under $\eta_{1}$, and will have strictly lower cost if the optimal contract under $\eta_{1}$ yields a positive rent. 
Observations 3 - there exists a high enough flat wage that implements an effort level for $\eta>0$ - and 4 - for $\eta \rightarrow \infty$ the First Best is arbitrarily closely approximated with a flat wage - also extend, though we have to be careful that the flat wage does not provide too large a rent (which would induce the agent to change to a higher action). Since effort costs are convex and expected revenue are concave, for a flat wage $u_{i}=\bar{u}+c(\hat{a})+\tilde{u}$ the two relevant IC's when $\hat{a}=a_{k}$ are:

$$
\eta \tilde{u}\left(E R(\hat{a})-E R\left(a_{k-}\right)\right) \geq c(\hat{a})-c\left(a_{k-1}\right) \quad \text { and } \quad \eta \tilde{u}\left(E R(\hat{a})-E R\left(a_{k+1}\right)\right) \geq c(\hat{a})-c\left(a_{k+1}\right) .
$$

Therefore the flat wage will implement $\hat{a}$ if $\frac{c\left(a_{k+1}\right)-c(\hat{a})}{\eta\left(E R\left(a_{k+1}\right)-E R(\hat{a})\right)} \geq \tilde{u} \geq \frac{c(\hat{a})-c\left(a_{k-1}\right)}{\eta\left(E R(\hat{a})-E R\left(a_{k-1}\right)\right)}$.

The interval is non-empty due to the the convexity of $c$ and the concavity of $E R$, demonstrating Observation 3, and the lower limit shrinks to zero in the limit as $\eta \rightarrow \infty$, demonstrating Observation 4 .

As in the two-action case, the lowest effort level can be implemented with a flat wage, and has the same cost as in the first best.

Lemma 6 If $\hat{a}=a_{1}$, then $u_{i}=\bar{u}+c(\hat{a})$ is the optimal contract for all $\eta$.

Proof. The $[\mathrm{IR}]$ holds with equality by construction. For each [IC] we have

$$
\begin{aligned}
\sum\left(\pi_{i}(\hat{a})-\pi_{i}\left(a^{\prime}\right)\right) u_{i}+\eta\left(\sum \pi_{i}(\hat{a}) u_{i}-c(\hat{a})-\bar{u}\right)\left(E R(\hat{a})-E R\left(a^{\prime}\right)\right) & \geq c(\hat{a})-c\left(a^{\prime}\right) \\
(\bar{u}+c(\hat{a})) \sum\left(\pi_{i}(\hat{a})-\pi_{i}\left(a^{\prime}\right)\right)+\eta\left((\bar{u}+c(\hat{a})) \sum \pi_{i}(\hat{a})-c(\hat{a})-\bar{u}\right)\left(E R(\hat{a})-E R\left(a^{\prime}\right)\right) & \geq c(\hat{a})-c\left(a^{\prime}\right) \\
0 & \geq c(\hat{a})-c\left(a^{\prime}\right)
\end{aligned}
$$

which is true since $c(\hat{a})<c\left(a^{\prime}\right)$ for all $a^{\prime}$. Since this contract has a cost to the principal equal to the first-best cost, it is optimal.

Next, we can show the standard result that for any optimal contract at least one downward [IC] will bind. Since both explicit and reciprocal incentives are costly, this ensures that at the optimum the principal is not providing excessive incentives.

Lemma 7 At the optimum, for at least one $a^{\prime}<\hat{a}$ we have

$$
\sum\left(\pi_{i}(\hat{a})-\pi_{i}\left(a^{\prime}\right)\right) u_{i}+\eta\left(\sum \pi_{i}(\hat{a}) u_{i}-c(\hat{a})-\bar{u}\right)\left(E R(\hat{a})-E R\left(a^{\prime}\right)\right)=c(\hat{a})-c\left(a^{\prime}\right) .
$$

Proof. Suppose instead that all downward [IC]s are slack. Then, since the principal's problem is a convex problem, we can drop all of these constraints without affecting the optimal solution. However, in this new problem $\hat{a}$ is the lowest-cost action, and therefore a 
flat wage such that the [IR] binds is optimal. However, in the full problem this contract will not implement $\hat{a}$ - therefore the assumption leads to a contradiction.

Lastly, we can show that for high enough $\eta$, the optimal contract is a reciprocity contract.

Proposition 13 There exists a finite $\eta^{*}$ such that for all $\eta \leq \eta^{*}$ the optimal contract is a standard contract (i.e. provides zero rent) and for all $\eta>\eta^{*}$ the optimal contract is a reciprocity contract (i.e. provides the agent with a strictly positive rent).

Proof. As before, we provide an upper bound on $\eta^{*}$ by showing that a flat wage can induce $\hat{a}$ strictly cheaper than the standard contract. Let $u_{s t}$ be the standard contract, and let $\dot{w}=\sum \pi_{i}(\hat{a}) h\left(u_{s t, i}\right)$. Again we consider the flat wage $u_{i}=u(\dot{w}-\epsilon)=\dot{u}$ for some small $\epsilon$. As before the [IR] will be strictly satisfied for $\epsilon$ small enough, and to satisfy the [IC]s we simply must satisfy the $[\mathrm{IC}] \mathrm{s}$ for $a_{k-1}$ and $a_{k+1}$ (where $\hat{a}=a_{k}$ ).

$$
\begin{array}{r}
\eta(\dot{u}-c(\hat{a})-\bar{u})\left(E R(\hat{a})-E R\left(a_{k-}\right)\right) \geq c(\hat{a})-c\left(a_{k-1}\right) \\
\eta(\dot{u}-c(\hat{a})-\bar{u})\left(E R(\hat{a})-E R\left(a_{k+1}\right)\right) \geq c(\hat{a})-c\left(a_{k+1}\right)
\end{array}
$$

which implies

$$
\frac{c\left(a_{k+1}-c(\hat{a})\right.}{(\dot{u}-c(\hat{a})-\bar{u})\left(E R\left(a_{k+1}\right)-E R(\hat{a})\right)} \geq \eta \geq \frac{c(\hat{a})-c\left(a_{k-1}\right.}{(\dot{u}-c(\hat{a})-\bar{u})\left(E R(\hat{a})-E R\left(a_{k-1}\right)\right)}
$$

The above condition will be satisfied for some finite $\eta$. Therefore the optimal positive-rent contract will have strictly lower cost than the optimal zero-rent contract (i.e. the standard contract), hence the optimal contract will be a reciprocity contract. For larger $\eta$, we know from Lemma 5 above, even smaller flat wages will continue to implement $\hat{a}$.

\subsubsection{Assuming CDFC}

We can extend all of the results from the two-action case if we can find assumptions that ensure that at the optimum only one $[\mathrm{IC}]$ binds (and therefore the FOC's have the same structure). To do so we need to demonstrate that for the optimal contract the agent's effort decision is a concave problem. Fortunately, the combination of the Monotone Likelihood Ratio Property (MLRP) and the Convexity of the Distribution Function Condition (CDFC), introduced by Rogerson (1985), is sufficient.

Let $F_{k}(a)=\sum_{i=1}^{k} \pi_{i}(a)$ denote the distribution function at state $\mathrm{k}$ given the action a. 
Definition 8 Convexity of the Distribution Function Condition (CDFC): CDFC holds if for $a<a^{\prime}<a^{\prime \prime}$ and for some $\alpha$ where $0 \leq \alpha \leq 1$ we have $c\left(a^{\prime}\right)=\alpha c\left(a^{\prime \prime}\right)+(1-\alpha) c(a) \quad$ then that implies $\quad F_{k}\left(a^{\prime}\right) \leq \alpha F_{k}\left(a^{\prime \prime}\right)+(1-\alpha) F_{k}(a) \forall k=1 \ldots n$.

Note that if CDFC holds, then $E R(a)$ is concave in $a$.

$$
\begin{aligned}
E R\left(a^{\prime}\right) & =\sum \pi_{i}\left(a^{\prime}\right) q_{i}=\sum F_{i}\left(a^{\prime}\right)\left(q_{i}-q_{i+1}\right)+q_{n} \\
& \geq \alpha\left(\sum F_{i}(a)\left(q_{i}-q_{i+1}\right)+q_{n}\right)+(1-\alpha)\left(\sum F_{i}\left(a^{\prime \prime}\right)\left(q_{i}-q_{i+1}\right)+q_{n}\right) \\
& =\alpha \operatorname{ER}(a)+(1-\alpha) \operatorname{ER}\left(a^{\prime \prime}\right)
\end{aligned}
$$

We can then prove that with MLRP and CDFC, the optimal contract will be nondecreasing.

Proposition 14 If MLRP and CDFC hold, then the optimal incentive scheme $u_{i}^{*}$ satisfies $u_{1} \leq u_{2} \leq \ldots \leq u_{n}$.

Proof. Consider the optimal contract for the relaxed problem where the agent can only choose an action from $\{a \mid a \leq \hat{a}\}$. We know at the optimum of this problem that

$$
h^{\prime}\left(u_{i}\right)=\lambda_{I R}+\sum \lambda_{k}\left(1-\frac{\pi_{i}\left(a_{k}\right)}{\pi_{i}(\hat{a})}+\eta\left(E R(\hat{a})-E R\left(a_{k}\right)\right)\right) .
$$

Since MLRP holds, at the optimum $u_{i}$ is non-decreasing. To show that this contract coincides with the optimal contract, it suffices to show that all of the $[\mathrm{IC}] \mathrm{s}$ for higher actions are satisfied.

Suppose to the contrary that a higher action is strictly preferred, i.e. for some $a^{\prime \prime}>\hat{a}$ we have

$\sum \pi_{i}(\hat{a}) u_{i}+\eta\left(\pi_{i}(\hat{a}) u_{i}-c(\hat{a})-\bar{u}\right) E R(\hat{a})-c(\hat{a})<\sum \pi_{i}\left(a^{\prime \prime}\right) u_{i}+\eta\left(\pi_{i}(\hat{a}) u_{i}-c(\hat{a})-\bar{u}\right) E R\left(a^{\prime \prime}\right)-c\left(a^{\prime \prime}\right)$

We know that a downward [IC] binds, i.e. for some $a^{\prime}<\hat{a}$ we have

$\sum \pi_{i}(\hat{a}) u_{i}+\eta\left(\pi_{i}(\hat{a}) u_{i}-c(\hat{a})-\bar{u}\right) E R(\hat{a})-c(\hat{a})=\sum \pi_{i}\left(a^{\prime}\right) u_{i}+\eta\left(\pi_{i}(\hat{a}) u_{i}-c(\hat{a})-\bar{u}\right) E R\left(a^{\prime}\right)-c\left(a^{\prime}\right)$

Also, for some $\alpha$ we have $c(\hat{a})=\alpha c\left(a^{\prime \prime}\right)+(1-\alpha) c\left(a^{\prime}\right)$, and from CDFC this implies 
$F_{k}(\hat{a}) \leq \alpha F_{k}\left(a^{\prime \prime}\right)+(1-\alpha) F_{k}\left(a^{\prime}\right)$. Therefore

$$
\begin{aligned}
& \sum \pi_{i}(\hat{a}) u_{i}+\eta\left(\pi_{i}(\hat{a}) u_{i}-c(\hat{a})-\bar{u}\right) E R(\hat{a})-c(\hat{a}) \\
= & \sum F_{i}(\hat{a})\left(u_{i}-u_{i+1}\right)+u_{n}+\eta\left(\pi_{i}(\hat{a}) u_{i}-c(\hat{a})-\bar{u}\right) E R(\hat{a})-c(\hat{a}) \\
\geq & \alpha\left[\sum F_{i}\left(a^{\prime \prime}\right)\left(u_{i}-u_{i+1}\right)+u_{n}+\eta\left(\pi_{i}(\hat{a}) u_{i}-c(\hat{a})-\bar{u}\right) E R\left(a^{\prime \prime}\right)-c\left(a^{\prime \prime}\right)\right] \\
& +(1-\alpha)\left[\sum F_{i}\left(a^{\prime}\right)\left(u_{i}-u_{i+1}\right)+u_{n}+\eta\left(\pi_{i}(\hat{a}) u_{i}-c(\hat{a})-\bar{u}\right) E R\left(a^{\prime}\right)-c\left(a^{\prime}\right)\right] \\
= & \alpha\left[\sum \pi_{i}\left(a^{\prime \prime}\right) u_{i}+\eta\left(\pi_{i}(\hat{a}) u_{i}-c(\hat{a})-\bar{u}\right) E R\left(a^{\prime \prime}\right)-c\left(a^{\prime \prime}\right)\right] \\
& +(1-\alpha)\left[\sum \pi_{i}\left(a^{\prime}\right) u_{i}+\eta\left(\pi_{i}(\hat{a}) u_{i}-c(\hat{a})-\bar{u}\right) E R\left(a^{\prime}\right)-c\left(a^{\prime}\right)\right]
\end{aligned}
$$

However, this contradicts the assumption that $a^{\prime \prime}$ is strictly preferred.

Additionally, since the optimal contract will be monotone, this ensures that the agent's problem is concave. Hence only the local downward [IC] will bind.

Proposition 15 If MLRP and CDFC hold, then at the optimum for implementing $\hat{a}=a_{k}$, only the $[I C]$ for $a_{k-1}$ binds.

Proof. The agent's problem is $\max _{a} \sum \pi_{i}(a) u_{i}+\eta\left(\sum \pi_{i}(\hat{a}) u_{i}-c(\hat{a})-\bar{u}\right) E R(a)-c(a)$ which is equivalent to $\max _{a} \sum F_{i}(a)\left(u_{i}-u_{i+1}\right)+u_{n}+\eta\left(\sum \pi_{i}(\hat{a}) u_{i}-c(\hat{a})-\bar{u}\right) E R(a)-c(a)$. Since we know $u_{i}$ is non-decreasing, therefore the first term is concave by CDFC. Similarly, we showed that $E R(a)$ is concave in $a$, and $c$ is convex. Therefore the agent's problem is concave, and so the local downward [IC] is sufficient for a global maximum.

Since only one $[\mathrm{IC}]$ is binding, then the multi-action case is equivalent to the two-action case where $\hat{a}=a_{k}$ and replacing $a_{1}$ with $a_{k-1}$. Therefore all our results from the two-action model extend.

Corollary 7 If MLRP and CDFC hold, then Propositions 2 to 5 and Corollaries 2 and 3 hold.

\section{References}

1. Akerlof, G.A. (1982) "Labor contracts as a partial gift exchange," Quarterly Journal of Economics, Vol. 97(4), pp. 543-569

2. Ashton, M.C. , S.V. Paunonen, E. Helmes, and D.N. Jackson (1998) "Kin Altruism, Reciprocal Altruism, and the Big Five Personality Factors," Evolution and Human Behavior, Vol. 19, pp. 243 - 255 
3. Autor, D.H. and D. Scarborough (forthcoming) "Does Job Testing Harm Minority Workers? Evidence from Retail Establishments," Quarterly Journal of Economics

4. Bartling, B. and F. von Siemens (2006) "The Intensity of Incentives in Firms and Markets: Moral Hazard with Envious Agents," Working Paper, University of Munich

5. Belfield, R. and D. Marsden (2003) "Performance pay, monitoring environments, and establishment performance," International Journal of Manpower, Vol. 24, pp. 452 471

6. Bellemare, C. and B.S. Shearer (2006) "Gift Exchange within a Firm: Evidence from a Field Experiment,' IZA Workingpaper No. 2696

7. Ben-Ner, A., F. Kong, and L. Putterman (2004a) "Share and share alike? Genderpairing, personality, and cognitive ability as determinants of giving," Journal of Economic Psychology, Vol. 25(5), pp. 581-589

8. Ben-Ner, A., L. Putterman, F. Kong, and D. Magan (2004b) "Reciprocity in a twopart dictator game," Journal of Economic Behavior 85 Organization, Vol. 53(3), pp. 333-352

9. Benjamin, D.J. (2006) "The Rotten Firm Theorem," Cornell University, mimeo

10. Bolton, G.E. and A. Ockenfels (2000) "ERC - A Theory of Equity, Reciprocity and Competition," American Economic Review, Vol. 90(1), pp. 166-193

11. Coffman, L. and M. Bazerman (2008) "Ethics and Strategic Intermediation," Harvard University, mimeo

12. Cox, J.C., D. Friedman, and V. Sadiraj (2008) "Revealed Altruism," Econometrica, Vol. $76(1)$, pp. 31-69

13. Dohmen, T., A. Falk, D. Huffman, and U. Sunde (2008) "Homo Reciprocans: Survey Evidence on Behavioral Outcomes," University of Bonn, mimeo

14. Dufwenberg, M. and G. Kirchsteiger (2004) "A Theory of Sequential Reciprocity," Games and Economic Behavior, Vol. 47, pp. 268-98

15. Dur, R. and A. Glazer (forthcoming) "Optimal Incentive Contracts when Workers envy their Bosses," Journal of Law, Economics, and Organization 
16. Englmaier, F. (2005) "A Survey on Moral Hazard, Contracts, and Social Preferences," in Psychology, Rationality and Economic Behaviour: Challenging Standard Assumptions, Bina Agarwal and Alessandro Vercelli, eds.

17. Englmaier, F. and S. Leider (2008) "Gift Exchange in the Lab and in the Field - It is not (only) how much you give ...," Harvard University, mimeo

18. Englmaier and Wambach (2005) "Optimal Incentive Contracts under Inequity Aversion," IZA Workingpaper No. 1643

19. Falk, A. (2007) "Gift-Exchange in the Field," Econometrica, Vol. 75(5), pp. 1501-1511

20. Falk, A. and U. Fischbacher (2006) "A Theory of Reciprocity," Games and Economic Behavior, Vol. 54(2), pp. 293-315

21. Fehr, E. and S. Gächter (2000) "Cooperation and Punishment in Public Goods Experiments," American Economic Review, Vol. 90(4), pp. 980 - 994

22. Fehr, E., G. Kirchsteiger, and A. Riedl (1998) "Gift Exchange and Reciprocity in Competitive Experimental Markets," European Economic Review, Vol. 42, pp. 1-34

23. Fehr, E., A. Klein, and K.M. Schmidt (2007) "Fairness and Contract Design," Econometrica, Vol. 75(1), pp. $121-154$

24. Fehr, E. and K.M. Schmidt (1999) "A Theory of Fairness, Competition and Cooperation," Quarterly Journal of Economics, Vol. 114(3), pp. 817-868

25. Fehr, E. and K.M. Schmidt (2003) "Theories of Fairness and Reciprocity - Evidence and Economic Applications" in M. Dewatripont et.al.(eds.) Advances in Economics and Econometrics, Eighth World Congress of the Econometric Society, Vol. 1 (Cambridge: Cambridge University Press), pp. 208-257

26. Geanakoplos, J. and D. Pearce, and E. Stacchetti (1989) "Psychological Games and Sequential Rationality," Games and Economic Behavior, Vol. 1, pp. 60-79

27. Gneezy, U. and J. List (2006) "Putting Behavioral Economics to Work: Field Evidence on Gift Exchange," Econometrica, Vol. 74(5), pp. 1365-1384

28. Grossman, S.J. and O.D. Hart (1983) "An Analysis of the Principal-Agent Problem," Econometrica, Vol. 51(1), pp. 7-45

29. Holmström, B. (1979) "Moral Hazard and Observability," Bell Journal of Economics, Vol. 10, pp. $74-91$ 
30. Holmström, B. and P. Milgrom (1991) "Multitask Principal-Agent Analyses: Incentive Contracts, Asset Ownership, and Job Design," Journal of Law, Economics and Organization, Vol. 7, pp. 24-52

31. Kim, S.K. (1995) "Efficiency of an Information System in an Agency Model," Econometrica, Vol. 63(1), pp. 89-102

32. Kosfeld, M. and F. von Siemens (2007) "Competition, Cooperation, and Corporate Culture," mimeo

33. Kube, S., C. Puppe, and M.A. Marechal (2006) "Putting Reciprocity to Work - Positive versus Negative Responses in the Field," mimeo

34. T. Lemieux, W.B. MacLeod, and D. Parent (2007) "Performance Pay and Wage Inequality," IZA DP No. 2850

35. Leshno, M., H. Levy, and Y. Spector (1997) “A Comment on Rothschild and Stiglitz's "Increasing Risk: I. A Definition"," Journal of Economic Theory, Vol. 77(1), pp. $223-228$

36. Leuven, E., H. Oosterbeek, R. Sloof, and C. van Klaveren(2005) "Worker reciprocity and employer investment in training," Economica Vol. 72(285), pp.137-149

37. Milgrom, P. and I. Segal (2002) "Envelope Theorems for Arbitrary Choice Sets," Econometrica, Vol. 70(2), pp. 583 - 601

38. Piekkola, H. (2005) "Performance-related pay and firm performance in Finland," International Journal of Manpower, Vol. 26(7/8), pp. 619-635

39. Prendergast, C. (1999) "The Provision of Incentives in Firms," Journal of Economic Literature, Vol. 37(1), pp. 7-63

40. Rabin, M. (1993) "Incorporating Fairness into Game Theory and Economics," American Economic Review, Vol. 83 (5), pp. 1281-1302

41. Rogerson, W.P. (1985) "The First-Order Approach to Principal-Agent Problems," Econometrica, Vol. 53(6), pp. 1357-1367

42. Rothschild, M. and J.E. Stiglitz (1970) "Increasing risk: I. A definition," Journal of Economic Theory, Vol. 2(3), pp. 225-243 


\section{CESifo Working Paper Series}

for full list see www.cesifo-group.org/wp

(address: Poschingerstr. 5, 81679 Munich, Germany, office@cesifo.de)

2353 Michael Kaganovich and Itzhak Zilcha, Alternative Social Security Systems and Growth, July 2008

2354 Keith Blackburn, Kyriakos C. Neanidis and M. Emranul Haque, Corruption, Seigniorage and Growth: Theory and Evidence, July 2008

2355 Edward Castronova, A Test of the Law of Demand in a Virtual World: Exploring the Petri Dish Approach to Social Science, July 2008

2356 Harald Badinger and Peter Egger, GM Estimation of Higher-Order Spatial Autoregressive Processes in Cross-Section Models with Heteroskedastic Disturbances, July 2008

2357 Wolfgang Buchholz and Jan Schumacher, Discounting the Long-Distant Future: A Simple Explanation for the Weitzman-Gollier-Puzzle, July 2008

2358 Luca Anderlini, Leonardo Felli and Alessandro Riboni, Statute Law or Case Law?, July 2008

2359 Guglielmo Maria Caporale, Davide Ciferri and Alessandro Girardi, Are the Baltic Countries Ready to Adopt the Euro? A Generalised Purchasing Power Parity Approach, July 2008

2360 Erkki Koskela and Ronnie Schöb, Outsourcing of Unionized Firms and the Impacts of Labour Market Policy Reforms, July 2008

2361 Francisco Alvarez-Cuadrado and Ngo Van Long, A Permanent Income Version of the Relative Income Hypothesis, July 2008

2362 Gabrielle Demange, Robert Fenge and Silke Uebelmesser, Financing Higher Education and Labor Mobility, July 2008

2363 Alessandra Casarico and Alessandro Sommacal, Labor Income Taxation, Human Capital and Growth: The Role of Child Care, August 2008

2364 Antonis Adam, Manthos D. Delis and Pantelis Kammas, Fiscal Decentralization and Public Sector Efficiency: Evidence from OECD Countries, August 2008

2365 Stefan Voigt, The (Economic) Effects of Lay Participation in Courts - A Cross-Country Analysis, August 2008

2366 Tobias König and Andreas Wagener, (Post-)Materialist Attitudes and the Mix of Capital and Labour Taxation, August 2008 
2367 Ximing Wu, Andreas Savvides and Thanasis Stengos, The Global Joint Distribution of Income and Health, August 2008

2368 Alejandro Donado and Klaus Wälde, Trade Unions Go Global!, August 2008

2369 Hans Gersbach and Hans Haller, Exit and Power in General Equilibrium, August 2008

2370 Jan P.A.M. Jacobs and Jan-Egbert Sturm, The Information Content of KOF Indicators on Swiss Current Account Data Revisions, August 2008

2371 Oliver Hülsewig, Johannes Mayr and Timo Wollmershäuser, Forecasting Euro Area Real GDP: Optimal Pooling of Information, August 2008

2372 Tigran Poghosyan and Jakob de Haan, Determinants of Cross-Border Bank Acquisitions in Transition Economies: A Latent Class Analysis, August 2008

2373 David Anthoff and Richard S.J. Tol, On International Equity Weights and National Decision Making on Climate Change, August 2008

2374 Florian Englmaier and Arno Schmöller, Reserve Price Formation in Online Auctions, August 2008

2375 Karl Farmer, Birgit Friedl and Andreas Rainer, Effects of Unilateral Climate Policy on Terms of Trade, Capital Accumulation, and Welfare in a World Economy, August 2008

2376 Monika Bütler, Stefan Staubli and Maria Grazia Zito, The Role of the Annuity’s Value on the Decision (Not) to Annuitize: Evidence from a Large Policy Change, August 2008

2377 Inmaculada Martínez-Zarzoso, The Impact of Urbanization on $\mathrm{CO}_{2}$ Emissions: Evidence from Developing Countries, August 2008

2378 Brian Roberson and Dmitriy Kvasov, The Non-Constant-Sum Colonel Blotto Game, August 2008

2379 Ian Dew-Becker, How Much Sunlight Does it Take to Disinfect a Boardroom? A Short History of Executive Compensation Regulation, August 2008

2380 Cécile Aubert, Oliver Falck and Stephan Heblich, Subsidizing National Champions: An Evolutionary Perspective, August 2008

2381 Sebastian Buhai, Miguel Portela, Coen Teulings and Aico van Vuuren, Returns to Tenure or Seniority?, August 2008

2382 Erkki Koskela and Jan König, Flexible Outsourcing, Profit Sharing and Equilibrium Unemployment, August 2008

2383 Torberg Falch and Justina AV Fischer, Does a Generous Welfare State Crowd out Student Achievement? Panel Data Evidence from International Student Tests, September 2008 
2384 Pedro Gomes and François Pouget, Corporate Tax Competition and the Decline of Public Investment, September 2008

2385 Marko Koethenbuerger, How Do Local Governments Decide on Public Policy in Fiscal Federalism? Tax vs. Expenditure Optimization, September 2008

2386 Ronald McKinnon and Gunther Schnabl, China’s Exchange Rate Impasse and the Weak U.S. Dollar, September 2008

2387 Yan-Leung Cheung, Yin-Wong Cheung and Alan T.K. Wan, A High-Low Model of Daily Stock Price Ranges, September 2008

2388 Louis Eeckhoudt and Harris Schlesinger, Changes in Risk and the Demand for Saving, September 2008

2389 Carsten Hefeker and Blandine Zimmer, Uncertainty and Fiscal Policy in an Asymmetric Monetary Union, September 2008

2390 Jay Pil Choi and Byung-Cheol Kim, Net Neutrality and Investment Incentives, September 2008

2391 Marcel Gérard, Financing Bologna, the Internationally Mobile Students in European Higher Education, September 2008

2392 Annette Alstadsæter and Knut Reidar Wangen, Corporations' Choice of Tax Regime when Transition Costs are Small and Income Shifting Potential is Large, September 2008

2393 António Afonso and Christophe Rault, 3-Step Analysis of Public Finances Sustainability: the Case of the European Union, September 2008

2394 Betsey Stevenson and Justin Wolfers, Economic Growth and Subjective Well-Being: Reassessing the Easterlin Paradox, September 2008

2395 Bernhard Eckwert and Itzhak Zilcha, Private Investment in Higher Education: Comparing Alternative Funding Schemes, September 2008

2396 Øystein Foros, Hans Jarle Kind and Jan Yngve Sand, Slotting Allowances and Manufacturers’ Retail Sales Effort, September 2008

2397 Mohammad Reza Farzanegan, Illegal Trade in the Iranian Economy: Evidence from a Structural Model, September 2008

2398 Olivier Bos, Charity Auctions for the Happy Few, September 2008

2399 Robert S. Chirinko and Debdulal Mallick, The Marginal Product of Capital: A Persistent International Puzzle, September 2008

2400 Ben D’Exelle and Arno Riedl, Elite Capture, Political Voice and Exclusion from Aid: An Experimental Study, September 2008 
2401 Torben M. Andersen and Joydeep Bhattacharya, On Myopia as Rationale for Social Security, September 2008

2402 Fabienne Llense, French CEO Compensations: What is the Cost of a Mandatory Upper Limit?, September 2008

2403 Valentina Bosetti, Carlo Carraro, Alessandra Sgobbi and Massimo Tavoni, Delayed Action and Uncertain Targets. How Much Will Climate Policy Cost?, September 2008

2404 Robert G. Chambers, Rolf Färe, Shawna Grosskopf and Michael Vardanyan, Generalized Quadratic Revenue Functions, September 2008

2405 Leonidas Enrique de la Rosa, Overconfidence in a Career-Concerns Setting, September 2008

2406 Marcus Drometer and Johannes Rincke, The Design of Political Institutions: Electoral Competition and the Choice of Ballot Access Restrictions in the United States, September 2008

2407 Markku Lanne and Helmut Lütkepohl, Stock Prices and Economic Fluctuations: A Markov Switching Structural Vector Autoregressive Analysis, September 2008

2408 Thomas L. Brewer, International Energy Technology Transfers for Climate Change Mitigations, September 2008

2409 Alexander Kemnitz, Native Welfare Losses from High Skilled Immigration, September 2008

2410 Xavier Vives, Strategic Supply Function Competition with Private Information, September 2008

2411 Fabio Padovano and Roberto Ricciuti, The Political Competition-Economic Performance Puzzle: Evidence from the OECD Countries and the Italian Regions, September 2008

2412 Joan Costa-Font and Mireia Jofre-Bonet, Body Image and Food Disorders: Evidence from a Sample of European Women, September 2008

2413 Thorsten Upmann, Labour Unions - To Unite or to Separate?, October 2008

2414 Sascha O. Becker and Ludger Woessmann, Luther and the Girls: Religious Denomination and the Female Education Gap in $19^{\text {th }}$ Century Prussia, October 2008

2415 Florian Englmaier and Stephen Leider, Contractual and Organizational Structure with Reciprocal Agents, October 2008 